\title{
Extreme bottom velocities induced by wind wave and currents in the Gulf of Gdańsk
}

\author{
Witold Cieślikiewicz $^{1}$ (D) Aleksandra Dudkowska ${ }^{1}$ - Gabriela Gic-Grusza ${ }^{1}$. \\ Jan Jędrasik ${ }^{1}$
}

Received: 31 December 2016/Accepted: 29 August 2017/Published online: 26 September 2017

(C) The Author(s) 2017. This article is an open access publication

\begin{abstract}
The principal goal of this study is to get some preliminary insights about the intensity of water movement generated by wind waves, and due to the currents in the bottom waters of Gulf of Gdańsk, during severe storms. The Gulf of Gdańsk is located in the southern Baltic Sea. This paper presents the results of analysis of wave and current-induced velocities during extreme wind conditions, which are determined based on long-term historical records. The bottom velocity fields originated from wind wave and wind currents, during analysed extreme wind events, are computed independently of each other. The long-term wind wave parameters for the Baltic Sea region are derived from the 44-year hindcast wave database generated in the framework of the project HIPOCAS funded by the European Union. The output from the numerical wave model WAM provides the boundary conditions for the model SWAN operating in high-resolution grid covering the area of the Gulf of Gdańsk. Wind current velocities are calculated with the M3D hydrodynamic model developed in the Institute of Oceanography of the University of Gdańsk based on the POM model. The three dimensional current fields together with trajectories of particle tracers spreading out of bottom boundary layer are modelled, and the calculated fields of bottom velocities are presented in the form of $2 \mathrm{D}$
\end{abstract}

This article is part of the Topical Collection on the 8th International Workshop on Modeling the Ocean (IWMO), Bologna, Italy, 7-10 June 2016

Responsible Editor: Ricardo de Camargo

Witold Cieślikiewicz

ciesl@ug.edu.pl

1 Institute of Oceanography, University of Gdańsk, Al. Piłsudskiego 46, 81-378 Gdynia, Poland maps. During northerly winds, causing in the Gulf of Gdańsk extreme waves and most significant wind-driven circulation, the wave-induced bottom velocities are greater than velocities due to currents. The current velocities in the bottom layer appeared to be smaller by an order of magnitude than the wave-induced bottom orbital velocities. Namely, during most severe northerly storms analysed, current bottom velocities ranged about $0.1-0.15 \mathrm{~m} / \mathrm{s}$, while the root mean square of wave-induced near-seabed velocities reached maximum values of up to $1.4 \mathrm{~m} / \mathrm{s}$ in the southern part of Gulf of Gdańsk.

Keywords Coastal zone $\cdot$ WAM $\cdot$ SWAN $\cdot$ POM $\cdot$ Gulf of Gdańsk hydrodynamics $\cdot$ Bottom velocities

\section{Introduction}

The knowledge on the size and structure of surface currents in the sea is much more advanced than the knowledge on current fields in deep sea and, in particular, near sea bottom. With the growth of a wide variety of human activity not only in the coastal zone, the demand for a good diagnosis of the bottom current values is very desirable. The velocities of these currents depend on the transfer processes of mass and momentum, and energy, but above all, on the forcing that occur in the layer of interaction with the atmosphere. Maximum velocity values are expected to appear during storm events. Currents and wind waves generated during most severe storms induce significant movement of bottom waters similar in scale to surface flow during mild weather conditions. The general aim of this study is to assess the kinematics of water particle motion in the bottom layer at transitional water depths characteristic for the sea areas beyond the surf zone, however, shallow enough for the wavy motion to reach the sea bottom during extreme storm events. 
Extreme events in the Baltic Sea are sometimes of unusual strength and persistence. The Baltic storms appear important phenomena from several points of view: first, as threatening to the safety of human activity and secondly, they may have beneficial effects on natural environment causing oxygenating inflows from the North Sea and refreshing waters in deeper layers, and in particular, the bottom waters. The third point is that the Baltic storms may set in motion the sediment transport in the coastal zone and may induce sedimentation processes at the bottom.

The subjects of our research have been extreme velocities of bottom flows generated by wind currents and wind waves in the Gulf of Gdańsk. Special attention is given to their formation during most severe storms. The severity of analysed storms is measured in terms of maximum significant wave height of the wave field generated by the storm in the Gulf of Gdańsk. The recognition of bottom flows was done by application of the latest generation wave and circulation models with downscaling to the Gulf of Gdańsk, for extreme storm conditions. The anticipated goals of this study include the analysis of bottom water motion generated by currents and wind waves during stormy conditions. In addition, the fields of significant wave heights, wave periods and mean direction of wave propagation have also been developed. On top of that, trajectories of the particle tracers released at the bottom water of SW Gulf of Gdańsk, and subsequently subjected to windinduced currents, were computed. The knowledge of circulation patterns of bottom currents and magnitude of their speeds allows for determining areas susceptible to erosion and sediment depositions.

Storminess over the basin of the Baltic Sea is owing to its location in the extra-tropics of the Northern Hemisphere. The most important influence on the regional climate exerts two large-scale pressure systems: the Icelandic Low and the Azores High (Rutgersson et al. 2015), represented by the North Atlantic Oscillation (NAO) index (Hurrell 1995). Growth of mean wind velocities in the 1960s and 1970s ensued from increasing in frequency of storms over the North and the Baltic Seas (1-2\% per year in a period 1958-2001, Weisse et al. 2005). The increase in storminess in the 1970s was most pronounced in NW Europe and was steadier in central Europe (Matulla et al. 2008). During the 1980s, most of the extreme storm events in terms of wind throw were connected with a positive NAO index associated with an increased number of extreme cyclones (Pinto et al. 2009). Some reanalysis suggested long-term upward trends in European storminess for the past 50 years mostly over northern Europe (Donat et al. 2011). Storminess and sea level variation on the Estonian coast during 1950-2011 was positively correlated with the NAO index (Jaagus and Suursaar 2013).

The last four decades of the previous century were dominated by the positive NAO phase. During that time, the Baltic waters were strongly atmospheric effects-driven via the increased number of storms. The surface current system was characterised by a wind speed-controlled increasing trend of current velocity $(0.02 \mathrm{~cm} / \mathrm{s}$ per 10 years, Jędrasik 2014). These findings correspond to the increasing trend of the significant wave height in the Baltic Sea (Cieślikiewicz et al. 2004), and the intensity of atmospheric system passage over the Baltic, and their correlation with the positive NAO index phase (Sepp 2009). An opposite relationship occurred during that time in the Mediterranean Sea. All the trends were referred to the NAO index changes with opposite consequences in the Baltic and the Mediterranean seas (Ruiz et al. 2008). Changes in the NAO index reflect alterations of atmospheric conditions which govern the nature of the $3 \mathrm{D}$ water circulation, sea level change and the frequency of oceanic inflows into the Baltic Sea (Jęrasik 2014).

An investigation of long-term changes in frequency of cyclones, which were formed in the northern Baltic Sea region in recent decades, showed that generally, the number of strong cyclones has not changed, but their mean and minimum air pressures have decreased significantly (Sepp et al. 2014). The results of the study by Sepp et al. (2005), Sepp (2009) revealed that percentage of the deep cyclones increased from $36 \%$ at the beginning to $47 \%$ at the end of the period 1948-2002. Statistically significant changes appeared mostly in winters. A study of climate variability and impact on the Baltic Sea area for the second part of the last century (1958-2009) revealed that the number and pathways of deep cyclones changed considerably in line with an eastward shift of the NAO centres of action. There was also a seasonal shift of strong wind events from autumn to winter and early spring (Lehmann et al. 2011).

For wind wave modelling over the whole Baltic Sea, the WAM model (WAMDI Group 1988) was applied in this study. The wave fields over the Gulf of Gdańsk were computed with use of the SWAN model (Booij et al. 1999). Modelling of currents was performed using the hydrodynamic model M3D (the Three Dimensional Model, Kowalewski 1997) developed in the Institute of Oceanography, University of Gdańsk (IOUG) based on the Princeton Ocean Model (POM, see Blumberg and Mellor 1987) and dedicated to the Baltic Sea.

SWAN was successfully applied in extreme wave conditions (see e.g. Guimarães et al. 2014) but not in the Baltic Sea. Although there were several studies focused on the modelling of wave field in this region (e.g. Jönsson et al. 2003, Soomere and Raamet 2011, Soomere et al. 2012), only in a few cases SWAN model was applied (Cieślikiewicz and Herman 2001, Reda and Paplińska 2002, Kriezi and Broman 2008).

POM was used to simulate hydrodynamics during extreme conditions like hurricanes (see e.g. Wang and Oey 2008, Oiao et al. 1999) also in the Baltic Sea (Dvornikov et al. 2017). Model based on POM codes was applied to the study of hydrodynamical conditions in selected regions of the Baltic by Svendsen et al. (1996), Jankowski (2000), Paka et al. (1998), 
Anisimov et al. (2000) and Zhurbas et al. (2003). At present, applications prepared by Jankowski (2002), Kowalewski (1997, 1998) and Herman and Jankowski (2001) are being used to analyse the wind-induced variability of hydrological parameters (including upwelling) in the coastal zone of the southern Baltic. However, neither SWAN nor POM was applied to estimate hydrodynamics during extreme weather conditions in the Gulf of Gdańsk. This work is the first devoted to this problem. Both WAM and M3D run regularly over the whole Baltic Sea and the Gulf of Gdańsk, and the modelling results are presented on a regular basis on the University of Gdańsk web pages. Detailed information about the models applied in the present work are given in the following section.

The knowledge of bottom velocity field is crucial to solve a number of engineering problems related to bottom erosion, sediment transport, and deposition of sediment. In this work, the maximal possible bottom velocities in the Gulf of Gdańsk are estimated. The Gulf of Gdańsk is an open bay in the southern Baltic Sea (see Fig. 1). Such near-bottom velocity data allows for investigation of bottom processes, for example the dynamics of sediments and the sea-floor evolution in specific locations. This investigation is an essential step in the preparation of development of marine infrastructure, such as dumping sites, deposition sites for dredged material and some other marine engineering facilities.

The area of the Gulf is $5850 \mathrm{~km}^{2}$ and its maximum depth is about $110 \mathrm{~m}$. The western part of the Gulf is the shallow Puck Bay, sheltered by Hel Peninsula. Although there are 31 surface sediment types identified in the Gulf of Gdańsk, the bottom is covered mainly by marine fine-grained sand that occurs in the coastal zone down to a depth of $38 \mathrm{~m}$ (almost one quarter of the area). Marine clay, marine clayey silt and marine silty clay are dominant at greater depths (for more details see Dudkowska and Gic-Grusza 2017).

Since the Baltic Sea is a non-tidal sea, the hydrodynamic conditions in the Gulf of Gdańsk depend mostly on the atmospheric conditions (winds), the Gulf's bottom topography (see Fig. 2) and inflow of Vistula river waters (see e.g. Robakiewicz 2000). Annual estuary outflow of the Vistula River equals $1040 \mathrm{~m}^{3} / \mathrm{s}$ and an absolute point of flood discharge increases up to $9190 \mathrm{~m}^{3} / \mathrm{s}$ (see Fal et al. 1997). In the study area, the westerly winds (from SW to NW) are dominant. Those conditions lead to the formation of large-scale cyclone circulation in the area of the Gulf observed as a field of quasi-permanent and geostrophic currents (Bobakov 2010). Even during strong wind events, wind currents are usually less than $0.5 \mathrm{~m} / \mathrm{s}$ (Kowalik 1990 based on a 2D hydrodynamic model).

In this paper, the basic hydrodynamic parameters of wind wave fields and currents, including velocity at the sea bottom, appearing in the Gulf of Gdańsk during the extreme weather conditions are estimated. For this purpose, two approaches are used.
1. The maximum wind speed over the central area of the Baltic Sea was estimated based on the 138-year NOAA data (Compo et al. 2011). For this extreme wind, a number of "artificial" storm wave fields with a homogeneous distribution of wind velocity vectors over the entire Baltic Sea were simulated for all cardinal and sub-cardinal wind directions.

2. Based on hindcast wind wave data, the 21 extreme historical storms in the period 1958-2001 have been selected and examined. The wind wave fields' characteristics over the Baltic Sea were taken from the 44-year hindcast generated within the framework of the project HIPOCAS (Cieślikiewicz et al. 2004; Cieślikiewicz and PaplińskaSwerpel 2008).

In the following section, applied wave and circulation models are described, as well as models' forcing and the configuration of model runs. Section 3 provides a description of the results of presented study, and in Section 4, a discussion of most important findings is given.

\section{Methods}

\subsection{Wave models}

The wave modelling performed in this study was done with the use of two spectral third-generation numerical wave models WAM (WAve Model) Cycle 4.5.2 (WAMDI Group 1988) and SWAN (Simulating WAves Nearshore) cycle III (Booij et al. 1999). Both WAM and SWAN determine the generation of waves by wind and wave propagation, taking into account a number of physical phenomena determining the wave field. These are mainly shoaling, refraction, non-linear interaction between waves and wave energy dissipation caused by whitecapping. The model SWAN, which is designed specifically for coastal sea areas, additionally includes energy dissipation by friction at the bottom and refraction due to ocean currents. Both wind wave numerical models applied in this study compute the directional spectral density of wave energy $\hat{F}(\sigma, \theta)$, where $\sigma$ is the so-called intrinsic radian frequency and $\theta$ is the direction angle of the wave spectral component propagation. The spectral density is an important characteristics of the free surface elevation of the wave $\zeta$. If $\mathbf{k}$ is the wave number vector and we take polar coordinates $(k, \theta)$ in the $\mathbf{k}$-plane, where $k=|\mathbf{k}|$, the radian frequency $\sigma$ fulfils the dispersion relation $\sigma^{2}=g k \tanh k h$, in which $g$ is the gravitational acceleration and $h$ is the water depth. If ambient currents are present, there is a frequency shift between $\sigma$ and the apparent radian frequency $\omega$, related to the Doppler effect. The frequency spectral density $S(\sigma)$ is defined as

$S(\sigma)=\int_{-\pi}^{\pi} \hat{F}(\sigma, \theta) d \theta$ 
Fig. 1 Study area with the location of points at which time series of wind were analysed (upper figure). The extent of computational grids for the SWAN model (lower figure)

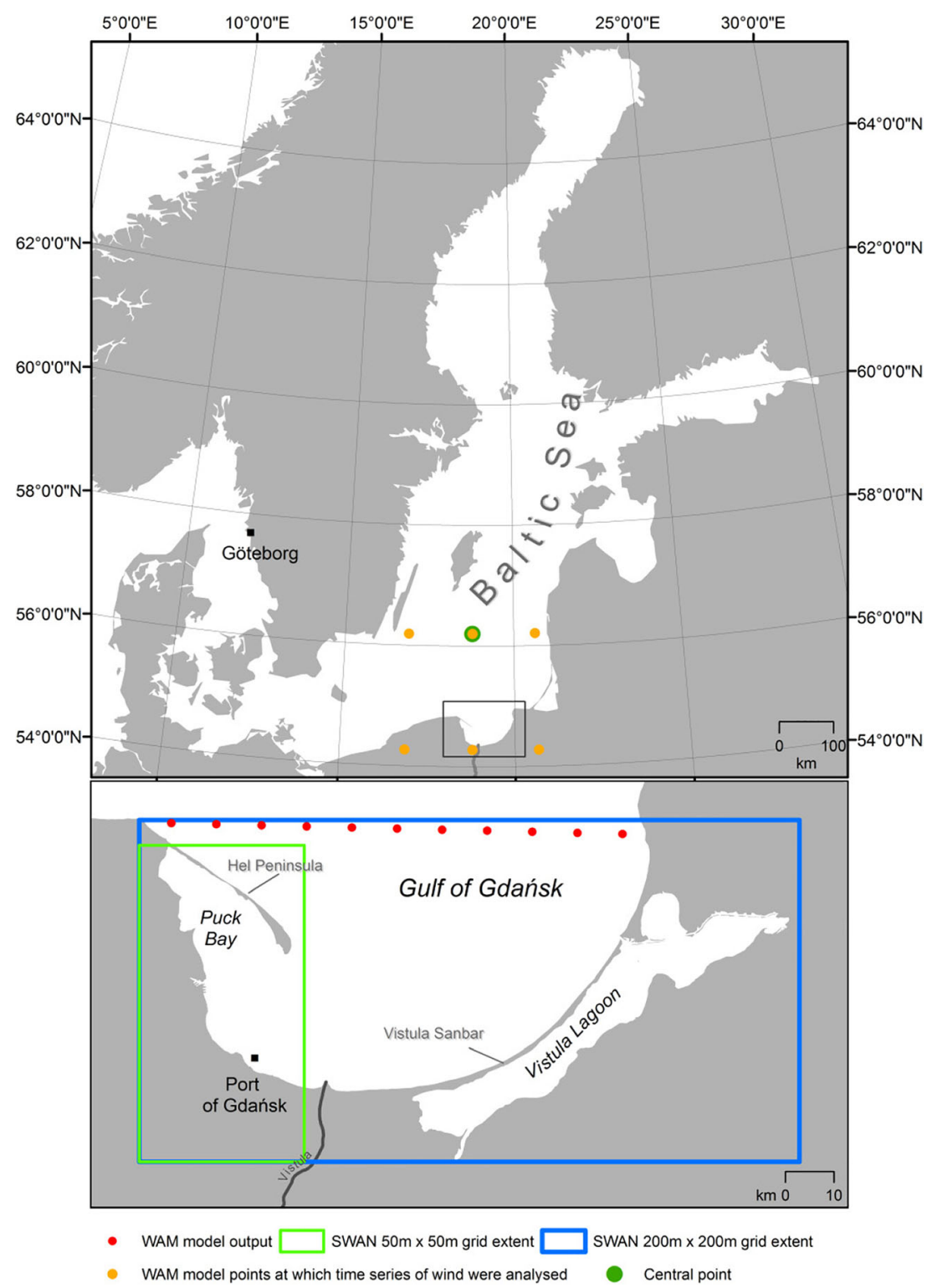

$\theta_{0}=\arctan \left(\frac{\int_{-\pi}^{\pi} \int_{0}^{\infty} \sin \theta \hat{F}(\sigma, \theta) d \sigma d \theta}{\int_{-\pi}^{\pi} \int_{0}^{\infty} \cos \theta \hat{F}(\sigma, \theta) d \sigma d \theta}\right)$

dom wind wave field may be calculated based on spectral moments $m_{n}$ :

$m_{n}=\int_{0}^{\infty} \sigma^{n} S(\sigma) d \sigma$

Using the spectral moments, the so-called integral wave parameters may be computed. For example, in this study, we use the following wave parameters: the significant wave height $H_{\mathrm{S}}$, the mean wave period $\bar{T}$, and the mean direction of wave propagation $\theta_{0}$. These parameters are defined in the following way:

$$
\begin{aligned}
& H_{\mathrm{S}}=H_{m_{0}}=4 \sqrt{m_{0}} \\
& \bar{T}=T_{m_{-1}}=2 \pi \frac{m_{-1}}{m_{0}}
\end{aligned}
$$

We will also use the peak period $T_{p}$ defined as

$$
T_{p}=1 / \sigma_{p}
$$

where $\sigma_{p}$ is the frequency for which the one-dimensional spectral density $S(\sigma)$ assumes its maximum value.

The WAM and the SWAN models numerically solve the energy balance equation and the wave action balance equation, respectively. The wave action $N(\sigma, \theta ; \mathbf{x}, t)$ is defined in terms of the wave spectral density $\hat{F}(\sigma, \theta ; \mathbf{x}, t)$ by the relation $N(\sigma, \theta ; \mathbf{x}, t)=\hat{F}(\sigma, \theta ; \mathbf{x}, t) / \sigma$, where $\mathbf{x}=\left[x_{1}, x_{2}\right]$ is the location vector on the horizontal plane and $t$ is the time. Both the energy and the wave action balance equations express the 
Fig. 2 Bottom topography of Gulf of Gdańsk

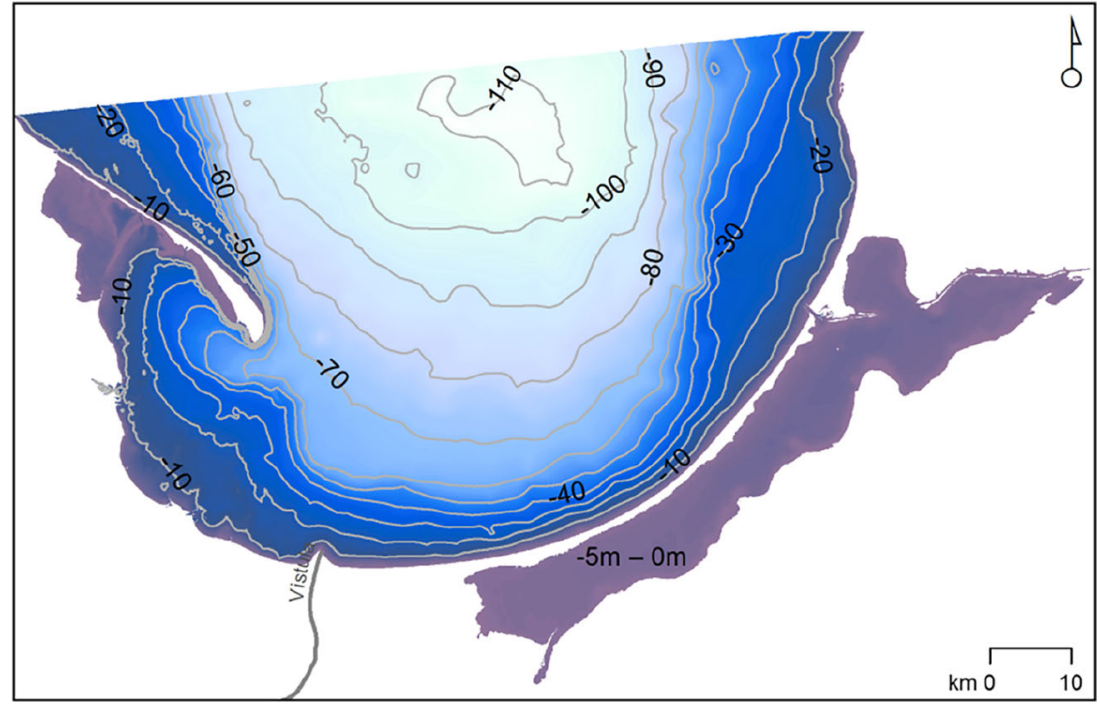

energy conservation law in the flux form with source terms. The energy balance equation in terms of the action density spectrum $N(\sigma, \theta ; \mathbf{x}, t)$ :

$\frac{\partial}{\partial t} N+\nabla \cdot\left(\boldsymbol{C}_{g} N\right)+\frac{\partial}{\partial \sigma}\left(c_{\sigma} N\right)+\frac{\partial}{\partial \theta}\left(c_{\theta} N\right)=\frac{D}{\sigma}$

is the most elegant formulation of the energy conservation law that is also valid if ambient currents are present (see e.g. Komen et al. 1996). When the currents are present, the energy spectrum balance equation needs to be supplemented with additional terms describing the wave-current interactions. The first term in Eq. (7) describes the local rate of change of the action density, while the second one represents the propagation of wave action $N$ in the geographical space $\left(x_{1}, x_{2}\right)$ with the absolute group velocity $\boldsymbol{C}_{g}=\partial \omega / \partial \mathbf{k}$ being the sum of the intrinsic group velocity $\boldsymbol{c}_{g}=\partial \sigma / \partial \mathbf{k}$ and the current velocity $\mathbf{U}$. The third term in (7) describes the change of the intrinsic frequency $\sigma$ due to varying bottom topography and the current field $-c_{\sigma}$ represents an abstract velocity of the wave action propagation in the $\sigma$-domain. Similarly, the velocity of the wave action propagation in the $\theta$-domain is represented by $c_{\theta}$ in the fourth term in the left hand side of (7), which describes the wave refraction due to varying both bottom topography and the current filed. The source term $D / \sigma$ on the right hand side of the wave action balance Eq. (7) includes the wave growth due to the wind action, non-linear resonant and nonresonant wave-wave interactions and the wave energy dissipation due to whitecapping and, in shallow water, the bottom friction and the depth-induced wave breaking.

\subsection{Ocean circulation model}

Wind-driven circulation patterns were obtained with the use of M3D model. As mentioned in the Sect. 1, this model is based on POM (Blumberg and Mellor 1987) and is dedicated to the
Baltic Sea. Due to specific conditions of this sea adjustments to the original POM were needed to allow for its effective adaptation (for details see Kowalewski 1997). One of the major modifications was introduced in the central difference scheme in advection transport equations. The conservative differential scheme ULTIMATE (Universal Limiter for Transient Interpolation Modelling of the Advective Transport Equations) based on the TVD (total variation diminishing) filter (Leonard 1991) was combined with the original POM central difference scheme, separately for each direction. As the ULTIMATE scheme ensures monotonicity of any one-dimensional, explicit advection numerical scheme, the procedure prevents oscillations and local extremes assuming unrealistic values (e.g. negative salinity) in the regions of great salinity gradients.

The nature of horizontal and vertical density distributions across the Baltic Sea, on the one hand, and the adoption of a $\sigma$ coordinate system on the other, implies the possibility for errors in determining the density gradients (Haney 1991) and the horizontal diffusion. To minimise such errors, a technique of subtraction of the area-averaged density before density gradient evaluation was applied (Kowalewski 1997). The Baltic Sea area was divided into sub-areas based on the similarities of the bottom topography, fluxes of energy across the sea surface and river inflow (see Fig. 3).

An open boundary in M3D setup is located between Skagerrak and Kattegat along the parallel connecting Skagen and Göteborg, where the exchange of waters with the North Sea takes place. A radiation condition based on the Sommerfeld's concept for vertically averaged and normal to the boarder plane velocities $V$ was applied (Hedley and Yau 1998):

$$
V=\frac{C}{h}\left(\eta-\eta^{\prime}\right)
$$


Fig. 3 Sub-regions of the Baltic Sea

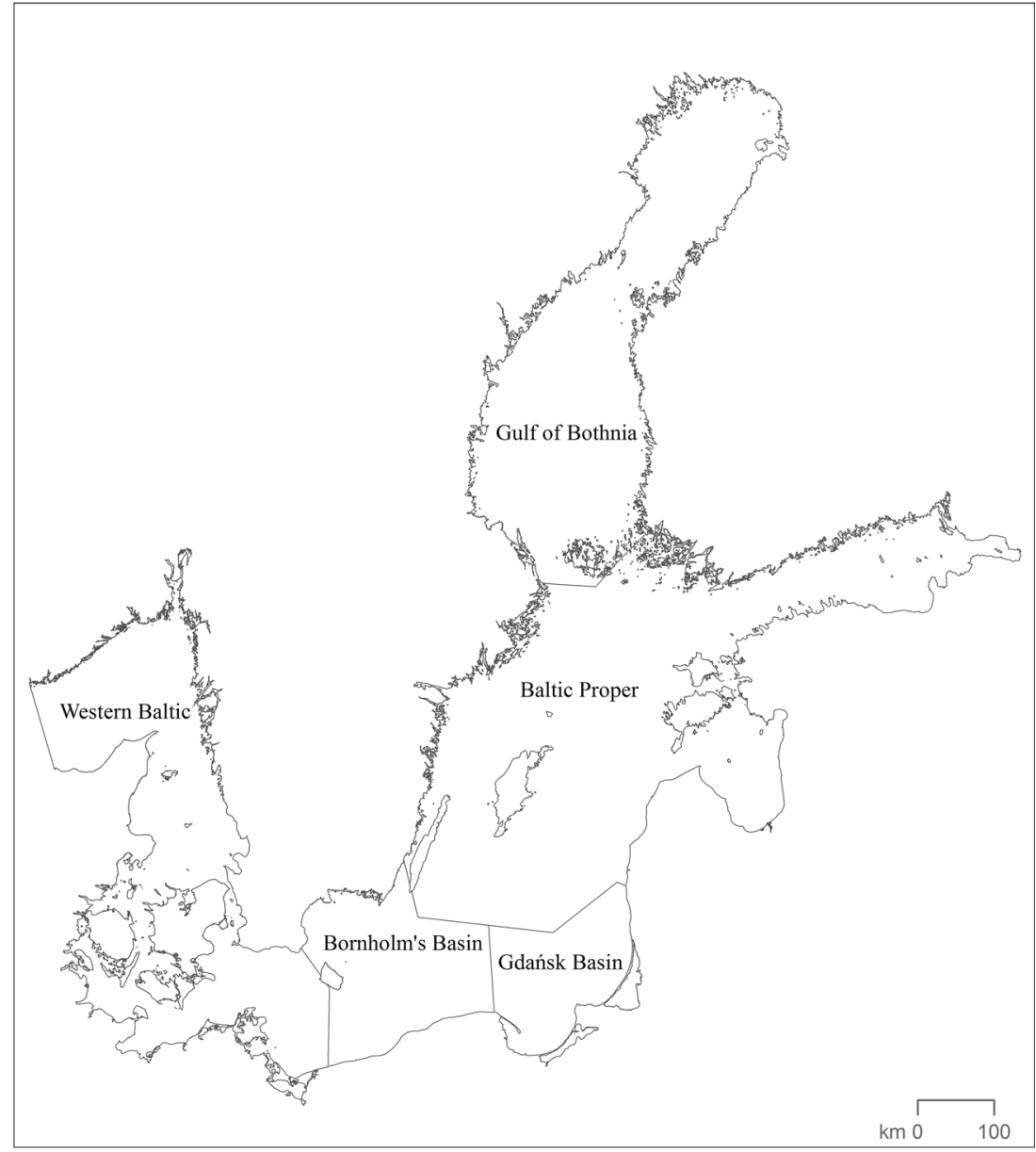

where $C=\sqrt{g h}$ and $\eta$ is a free surface elevation defined as the mean of the surface elevation values for grid points on both sides of the open boundary calculated based on the continuity equation; $\eta^{\prime}$ denotes a free surface elevation observed in the vicinity of the open boundary. The applied approach provides the smallest reflection effects. It should be emphasised that the meaning of the free surface elevation $\zeta$ used in Sect. 2.1 to describe wind wave physics differs from the meaning of $\eta$ discussed here. The water surface elevation $\eta$ in the context of wind-driven circulation does not incorporate the short-period wind wave motion and should be considered as the mean sea surface elevation, i.e. the time average over many wind wave periods.

The surface boundary conditions for heat fluxes were described by bulk formulae analogous to this used in POM and parametrised according to the energy exchange across the sea surface through short (Kreżel 1997) and long wave radiation and sensible and latent heat transfer (Jędrasik 1997 and later revision by Herman et al. 2011). Wind stress drag coefficients were parameterised according to Hellerman and Rosenstein (1983).

The M3D model was the subject of comprehensive validation against long-term observations of sea level, salinity and temperature. For details, see Jędrasik and Cyberski (2000), Kowalewski (2002), Kannen et al. (2004), Jędrasik (2005), Jędrasik et al. (2008), Zdroik and Jędrasik (2009) and Kowalewski and KowalewskaKalkowska (2011). The modelled sea surface temperature fields were also compared to those obtained from the satellite SST images giving satisfactory results which are documented in Jędrasik (2005) and Kowalewski et al. (2009). The high quality of M3D model simulations was also shown in relation to observed values with respect to spatial and seasonal variability in shallow and deep coastal waters as well as in the open sea. The results of comparisons between the modelled and observed values indicated the high quality of simulations by the M3D hydrodynamic model (Jędrasik 2005; Jędrasik et al. 2008).

\subsection{Bathymetry and models forcing}

The bathymetry data for the Baltic Sea, used as input to the WAM and M3D models, were provided by the Institut für Osteseeforschungin Warnemünde (IOW) (see Seifert and Kayser 1995). These data were subjected to a very careful examination and then adapted to the wave 
model requirements. For the modelling of waves in the Gulf of Gdańsk, bathymetric data provided by IOUG and the Gdynia Naval Hydrographic Office in digital form, prepared by the Maritime Institute in Gdańsk (MIG), was used. The bathymetry for M3D model was constructed based on survey data from IOW, IOUG, MIG and the Gdynia Naval Hydrographic Office.

In order to get some idea of hydrodynamic regimes, in particular the wave- and current-induced bottom velocity distributions existing during extreme meteorological conditions, characterised by persistent very strong wind blowing from different directions, eight artificial "uniform" storms have been created. For each of these storms, the stationary in time and homogeneous in space wind velocity field was defined. The assumed wind velocity vectors were oriented in all eight cardinal and subcardinal directions, resulting in having different eight wind velocity fields (eight storms). For each of these eight artificial storms, a constant wind speed of magnitude $30 \mathrm{~m} / \mathrm{s}$ was selected as approximately equal to the maximum wind speed of $30.5 \mathrm{~m} / \mathrm{s}$ found in the 138 -year period of NOAA, 20CR data for a grid point selected for the central area of the Baltic Sea.

As it was already mentioned above, all SWAN model simulations were performed under the assumption of stationary in time and uniform in space wind blowing in the direction prevailing over the Gulf area. The boundary wave data corresponding to extreme storm conditions were obtained by applying WAM model results:

- Extracted from the HIPOCAS hindcast dataset, for the 21 selected severe historical storms that appeared to be extreme, with respect to significant wave height computed for a grid point located in the central area of the Gulf-these storms are listed in Table 1, in which the maximum significant wave heights $H_{\mathrm{S}}$ on the northern border of Gulf of Gdańsk, for the peaks of the storms, are also given together with the average wind speeds $U_{10}^{(1)}$ and $U_{10}^{(2)}$ used during the SWAN simulations over the $200 \mathrm{~m} \times 200 \mathrm{~m}$ (whole Gulf of Gdańsk area) and the $50 \mathrm{~m} \times 50 \mathrm{~m}$ (Puck Bay) grids, respectively

- Computed for uniform wind velocity vector fields, with the assumed wind speed equal to $30 \mathrm{~m} / \mathrm{s}$, and for eight cardinal and intercardinal geographical directions $(\mathrm{N}$, NE, etc.), with the use of IOUG setup established within the PROZA project (Cieślikiewicz et al. 2014)

Details of the input data applied in this study for numerical experiments performed with M3D model are presented in Table 2.

\subsection{Configuration of numerical runs}

We assume in this work that the maximal velocities occur during the extreme wind conditions. The maximum value of the wind speed over the central area of the Baltic Sea was estimated in this study based on 138-year NOAA, 20CR (the Twentieth Century Reanalysis, Compo et al. 2011) dataset. The 20CR dataset provides the first estimates of wind direction and speed from 1871 to 2008 at 6-hourly temporal and $2^{\circ}$ spatial resolutions (see for more detail Cieślikiewicz et al. 2016). The maximum wind speed in the 138-year period considered was $U_{\max }$ of $30.5 \mathrm{~m} / \mathrm{s}$ at the WSW direction. Based on these findings, for the hypothetical extreme meteorological conditions that have been defined within the study and then utilised in the modelling of wind wave and wind current fields, for assumed artificial uniform wind fields over the whole Baltic Sea, for eight selected main directions of the wind (W, NW, N, NE, E, SE, S, SW), the wind speed $U_{10}$ (wind speed at $10 \mathrm{~m}$ above the sea surface) of $30 \mathrm{~m} / \mathrm{s}$ was applied. Bottom-velocity fields originated from wind wave and wind currents during these extreme wind conditions were calculated independently to each other, and velocity fields related to the wave-induced currents have been neglected. There have been a number of studies carried out in recent years indicating that wave-current interactions play a role in shaping hydrodynamic conditions in the sea. However, most of those studies focus on wave interaction with tidal currents, which are frequently of significant magnitude, especially in shallow areas close to the shore. The Baltic Sea is a non-tidal sea and the wave-current interactions, in general, do not play a significant role (Cieślikiewicz and Herman 2002). Thus, at the present stage of this study, we apply a simpler approach with the interactions between wind wave and current phenomena not taken into account.

The wind wave parameters for the Baltic Sea region taken from the model WAM running in the coarse resolution grid establishes the boundary conditions for the model SWAN (Booij et al. 1999) operating in high-resolution grid covering the area of Gulf of Gdańsk.

Modelling of currents was performed using the hydrodynamic model M3D. The solution includes both the whole Baltic Sea and the Gulf of Gdańsk connected as a sub-area by a two-way downscaling, i.e. two-way exchange of common boundary information at every computational time step. The variables evaluated at the border of one region served as the boundary conditions for the other. The three-dimensional current fields together with trajectories of particle tracers spreading out of bottom boundary layer are modelled. The analysis of the obtained particle tracer trajectories may provide some insight into the problem of sediment movement. 
Table 1 Storm dates and corresponding boundary conditions for SWAN simulations. Most severe storm is indicated with italic

\begin{tabular}{|c|c|c|c|c|c|c|c|}
\hline & Year & Month & Day & Hour & $H_{\mathrm{S}}[\mathrm{m}]$ & $U_{10}^{(1)}[\mathrm{m} / \mathrm{s}]$ & $U_{10}^{(2)}[\mathrm{m} / \mathrm{s}]$ \\
\hline Storm 1 & 1959 & April & 19 & 13.00 & 5.43 & 14.68 & 13.46 \\
\hline Storm 2 & 1961 & December & 21 & 8.00 & 6.29 & 13.33 & 12.08 \\
\hline Storm 3 & 1962 & February & 18 & 3.00 & 7.67 & 16.61 & 14.63 \\
\hline Storm 4 & 1962 & February & 21 & 4.00 & 7.52 & 15.18 & 13.90 \\
\hline Storm 5 & 1967 & November & 19 & 5.00 & 6.14 & 12.69 & 11.47 \\
\hline Storm 6 & 1975 & November & 21 & 11.00 & 6.94 & 14.52 & 12.86 \\
\hline Storm 7 & 1976 & December & 26 & 11.00 & 6.45 & 13.79 & 12.11 \\
\hline Storm 8 & 1983 & January & 20 & 2.00 & 7.30 & 15.09 & 13.43 \\
\hline Storm 9 & 1986 & April & 10 & 19.00 & 5.95 & 14.86 & 14.33 \\
\hline Storm 10 & 1988 & November & 29 & 23.00 & 8.53 & 16.09 & 13.96 \\
\hline Storm 11 & 1988 & December & 14 & 21.00 & 6.88 & 13.79 & 12.87 \\
\hline Storm 12 & 1989 & October & 1 & 0.00 & 6.30 & 13.49 & 11.81 \\
\hline Storm 13 & 1989 & December & 7 & 14.00 & 6.97 & 13.99 & 12.21 \\
\hline Storm 14 & 1992 & January & 17 & 11.00 & 8.29 & 17.17 & 14.72 \\
\hline Storm 15 & 1992 & October & 12 & 4.00 & 6.73 & 12.28 & 11.67 \\
\hline Storm 16 & 1992 & November & 8 & 15.00 & 6.85 & 14.95 & 13.13 \\
\hline Storm 17 & 1995 & August & 31 & 11.00 & 5.33 & 14.28 & 13.93 \\
\hline Storm 18 & 1997 & April & 11 & 23.00 & 8.10 & 16.82 & 15.12 \\
\hline Storm 19 & 1998 & January & 31 & 13.00 & 7.29 & 14.98 & 13.96 \\
\hline Storm 20 & 2000 & January & 21 & 6.00 & 7.57 & 15.51 & 13.74 \\
\hline Storm 21 & 2001 & April & 13 & 12.00 & 5.64 & 14.17 & 13.12 \\
\hline
\end{tabular}

\subsubsection{Extreme wind conditions, test cases}

The maximum possible bottom velocities result from extreme wind conditions. As test cases, the 21 historical extreme storms over the Gulf of Gdańsk were selected. This was done by the automatic search over the 44-year long significant wave height $H_{S}$ time series taken from the HIPOCAS data base, for the central point of the Gulf within the time period 1958-2001, with a threshold set to $H_{S}=2.8 \mathrm{~m}$ (for details see Cieślikiewicz et al. 2016). Next, the wave fields over the Gulf of Gdańsk were computed with use of the SWAN model, with the open boundary conditions on the northern border of Gulf of Gdańsk taken from the HIPOCAS database (see Table 1). For the same 21 historical storm conditions, the wind-induced circulation in the Gulf of Gdańsk was computed using the IOUG M3D model.

In order to reconstruct and investigate the hydrodynamic regime in the study area, the eight artificial storms with uniform wind fields over the Baltic Sea were simulated, namely the wave and current fields were computed over the whole Baltic Sea, using WAM, SWAN and M3D models. As wind input to the models, the eight wind fields homogeneous over the entire Baltic Sea for W, NW, N, NE, E, SE, S and SW wind directions and wind speed of $30 \mathrm{~m} / \mathrm{s}$ were used. The assumed wind velocity value is close to the extreme wind velocity, estimated for the central area of the Baltic Sea (Fig. 1) based on the 138-year NOAA data (Compo et al. 2011) - for detailed methodology, see Cieślikiewicz et al. (2016). As far as the extreme wind speed is concerned, it can be expected that the wind data, essentially based on numerical modelling with assimilated observations, do not reflect a realistic maximum values of wind speed fluctuations. However, since modelled meteorological data are used for the modelling of sea hydrodynamics, the adoption of wind speed of $30 \mathrm{~m} / \mathrm{s}$ may be considered appropriate. It should be emphasised that wave field modelling for artificial homogeneous wind fields with different wind directions (W, NW, N, NE, E, SE, S, SW) is aimed to identify the main characteristic features of hydrodynamic conditions corresponding to different meteorological regimes. Those conditions, obtained by numerical computations, do not reflect the real sea states, and the assumed extreme value of wind speed may only generate the extreme storm conditions to some approximate accuracy. The authors believe this approach allows examining the principal features of extreme storm wave and circulation in the studied sea area. All of the 29 test cases analysed ( 21 hindcast historical and 8 artificial uniform storms) are considered to reflect the most extreme hydrodynamic conditions one can expect in the Gulf of Gdańsk. 
Table 2 Input data for M3D numerical experiments

“Artificial” storms Historical storm no. 10 experiments

\begin{tabular}{|c|c|c|}
\hline $\begin{array}{l}\text { ea level in the } \\
\text { vicinity of the } \\
\text { open boundary } \\
(\eta)\end{array}$ & \multicolumn{2}{|c|}{$\begin{array}{l}\text { Observed sea level at Göteborg station every each } \\
\text { hour, from the period 1-6 January } 1994\end{array}$} \\
\hline $\begin{array}{l}\text { in the } \\
\text { ty of the } \\
\text { boundary }\end{array}$ & \multicolumn{2}{|c|}{$\begin{array}{l}\text { Monthly averaged vertical distribution of salinity } \\
\text { along the cross section Skagen-Göteborg, from } \\
\text { the International Council for the Exploration of } \\
\text { the Sea (ICES) Data Portals }\end{array}$} \\
\hline of & \multicolumn{2}{|c|}{$\begin{array}{l}\text { Climatic observational data of the Baltic Seafor the } \\
\text { period 1994-1996, from the Baltic } \\
\text { Environmental Database (BED) }\end{array}$} \\
\hline $\begin{array}{l}\text { Tetec } \\
\text { hea } \\
\text { cal }\end{array}$ & $\begin{array}{l}\text { he European Centre } \\
\text { for Medium-Range } \\
\text { Weather Forecasts } \\
\text { (ECMWF) from the } \\
\text { period 1-6 January } \\
1994\end{array}$ & $\begin{array}{l}\text { EMO data (Jan. 1, 1988, } \\
\text { Feb. 12, 1988), the } \\
\text { period of September and } \\
\text { October for model } \\
\text { spin-up }\end{array}$ \\
\hline III & \multicolumn{2}{|c|}{$\begin{array}{l}\text { Monthly averaged riverine water outflow of } 152 \\
\text { rivers floating into the Baltic for period } \\
1970-2010 \text { from the Baltic Nest Institute of in } \\
\text { Sweden }\end{array}$} \\
\hline
\end{tabular}

\subsubsection{Wind waves-open sea}

The long-term wind wave parameters for the Baltic Sea region are derived from the 44-year hindcast wave database generated in the framework of the project HIPOCAS (Cieślikiewicz et al. 2004, Cieślikiewicz and Paplińska-Swerpel 2008). This dataset was produced using the WAM model with the meteorological forcing data being the 1-hourly gridded wind velocity fields extracted from the atmospheric reanalysis dataset (see Cieślikiewicz and Paplińska-Swerpel 2008). The wind wavefiled hindcast utilised in this study was conducted over the period 1958-2001. The modelling area covers the whole Baltic Sea together with the Danish Straits. The spatial grid is regular in spherical rotated coordinate system, with resolution $5^{\prime} \times 5^{\prime}$ (about $9.26 \mathrm{~km}$, i.e. $5 \mathrm{Nm}$, in the modelled area). The grid for wave modelling with WAM is rotated in such a way that the equator is located above the centre of the modelling area, to achieve a minimum distortion of the grid boxes. The geographical spherical co-ordinate system is rotated by two Eulerian angles - firstly by $19.3^{\circ}$ about the Earth's axis and then in the plane of the "new" meridian $0^{\circ}$, by the angle equal to $-56^{\circ}$.

In spectral space, the 25 frequencies ranging from 0.050545 to $0.497855 \mathrm{~Hz}$ and corresponding to the wave periods from 2 to $19.8 \mathrm{~s}$ were used; the directional resolution was equal to $15^{\circ}$. The input wind data were converted and interpolated in space into the wave model computational grid. In time domain, the wind fields were interpolated within the WAM model and the output wind time step has been set to $300 \mathrm{~s}$.

\subsubsection{Wind waves-the Gulf and coastal zone}

In the coastal zone, wind waves are subject to strong transformation, associated with decreasing depths and increasing bottom friction. This transformation consists mainly of reducing the wavelength and increasing the wave height, to reach a certain critical value, at which the waves break, and changing the angle of approach - wave refraction and diffraction. Wave energy is dissipated and converted into other forms of motion, e.g. wave-induced currents and turbulence. To estimate the approximate values of the wind-wave parameters in the Gulf of Gdańsk, the SWAN model was used as a more suitable model for wave forecasting in such sea areas. The application of the model in the Gulf of Gdańsk was described in many publications (see e.g. Cieślikiewicz et al. 2016).

Within this research study, the output from model WAM running over the whole Baltic Sea in the coarse resolution grid establishes the boundary conditions for the model SWAN operating in high-resolution grid covering the area of Gulf of Gdańsk. While hindcasting with SWAN the 21 selected historical storms, the boundary condition data were extracted from the HIPOCAS wave parameter database. For modelling of the eight created artificial uniform storms, the WAM model implementation and setup developed in IOUG within the PROZA project (Cieślikiewicz et al. 2014) has been applied.

The SWAN model simulations were conducted in two steps. The first one was associated with computations on a grid with a spatial resolution of $200 \mathrm{~m} \times 200 \mathrm{~m}$, covering the entire Gulf of Gdańsk. In the second step, computations were performed over the Puck Bay using the grid with spatial resolution of $50 \mathrm{~m} \times 50 \mathrm{~m}$. The extent of these grids is shown in Fig. 1. In the case of coarser grid, the hydrodynamic boundary conditions were given in the form of monochromatic wave parameters that were set on the Gulf of Gdańsk open northern border. This northern border of the coarser computational grid of the SWAN model includes 11 WAM grid points, as shown in Fig. 1. Output of simulations in the first step provided the boundary conditions for the simulation on a nested Puck Bay grid. In both cases, homogenous wind field of a predetermined direction and speed was assumed. All the SWAN simulations were performed in stationary mode, and the results are given for the peak of each storm.

\subsubsection{Wind-driven circulation}

In all the numerical experiments conducted within this work, the relatively coarse horizontal grid over the whole Baltic Sea, with the resolution of $9.26 \mathrm{~km}(5 \mathrm{Nm})$, was applied. The embedded finer grid for covering the Gulf of Gdańsk has the resolution of $1.852 \mathrm{~km}(1 \mathrm{Nm})$. The vertical resolution in the column of water has been assumed as $18 \sigma$-layers with the layer width finer near the surface and bottom. The subsequent widths from the sea surface to bottom were $0.0054,0.0054$, 
$0.0104,0.0208,0.0417,0.0833$ for $\sigma$-levels $6-15,0.0417$, 0.0208 and 0.0208 . The thickness of the bottom layer was assumed to be about $2 \%$ of water depth at each node of the grid $(\Delta \sigma=0.0208 h)$. The time steps were $600 \mathrm{~s}$ and $60 \mathrm{~s}$ for baroclinic currents and barotropic mode, respectively.

Apart from the 3D velocity fields, simulated routes of virtual particle tracers localised initially near the bottom in the two points in the Gulf of Gdańsk have been "observed". As the particle tracers represent selected sea water elements, the obtained trajectories allowed performing the analysis of evolution of the three-dimensional flow described by the equations of both the horizontal and vertical advection and diffusion. The coordinates of positions of the virtual particle tracers (longitude, latitude, depth) were specified in time step intervals assumed in computations of baroclinic currents, i.e. $600 \mathrm{~s}$.

\section{Results}

The main results of this study are computed fields of bottom velocity resulting from wind wave and currents during extreme wind conditions. Within this work, the effect of mutual interactions between currents and waves was neglected, thus the values of wind wave- and current-generated bottom velocities were calculated separately for all the 29 test cases (21 historical hindcast and 8 artificial uniform storms).

Bottom currents in the Gulf of Gdańsk induced by winds of $30 \mathrm{~m} / \mathrm{s}$ blowing from eight cardinal and intercardinal geographical directions (W, NW, etc.) have been analysed. Those bottom current velocity fields are presented in Fig. 4. Particular attention was put on the order of velocities and appearing circulation patterns. In Fig. 4, five ranges of velocities are presented and marked with different colours. These are $0-0.05,0.05-0.1,0.1-0.2,0.2-0.3$ and $0.3-0.55 \mathrm{~m} / \mathrm{s}$. These fields computed for the eight artificial test cases have shown different orders of module of generated velocities and different locations of eddies induced.

As the result, the calculated fields of bottom velocities are presented. It is shown that the maximal velocities occur during northerly winds, and generally, the wave-induced velocities are much greater than the current velocities. Only for southerly winds the values of wave-induced and current bottom velocities are comparable.

It is interesting to take a closer look at two bottom velocity fields induced by opposite winds, from $\mathrm{N}$ and $\mathrm{S}$ directions. One can see in Fig. 4 that the northern winds generated two eddies exceeding beyond the open border of the Gulf. In the western part of it, a cyclonic eddy with the largest velocities $0.30-0.55 \mathrm{~m} / \mathrm{s}$ of bottom currents became very clear. At the eastern part of the Gulf, an anticyclonic asymmetric and meridionally elongated eddy with velocities of order $0.1-0.3 \mathrm{~m} / \mathrm{s}$ appeared. At the southwest part of the Gulf, bottom currents of $0-0.2 \mathrm{~m} / \mathrm{s}$ outflow heaped waters towards the open boundary.
At sheltered waters of the Puck Bay, the bottom currents were characterised by the smallest velocities of order $0.05-0.1 \mathrm{~m} / \mathrm{s}$. In contrary to that situation, when southern winds are prevailing, because of the short wind fetch, only local anticyclonic vortex got induced in the Puck Bay with velocities of 0.1$0.3 \mathrm{~m} / \mathrm{s}$ as well as intensive bottom currents of order of $0.5 \mathrm{~m} / \mathrm{s}$ at both sides (western and eastern) of the Gulf in the region open boundary appeared. Bottom currents opposite to wind direction with velocities of $0.1-0.2 \mathrm{~m} / \mathrm{s}$ prevailed at the southern area of Gdańsk Bay. Noteworthy is dominance of central area over the Gdańsk Deep by the smallest velocities of currents of order $0-0.05 \mathrm{~m} / \mathrm{s}$.

Winds blowing from the northern sector induce up to two couples of opposite to each other (cyclonic and anticyclonic) eddies in the near-bottom layer. Northern and northwest winds generated strong cyclonic eddy in the western open part of the Gulf as well as smaller and weaker anticyclonic eddy placed at its eastern part. The north-eastern wind caused appearance of small cyclonic eddy pattern in the Puck Bay, and a dominant anticyclonic vortex covered the remaining area of the Gulf. The opposite wind from southwest generated two small eddies: the cyclonic one located at the Puck Bay and the not too large other eddy appearing along the Vistula Sandbar in the south-eastern part of the Gulf. Winds from south and southeast resulted in revealing of local anticyclonic bottom vortexes in the western part of the Gulf and certain intensification of bottom flows in its eastern area. Winds blowing from latitudinal directions (western and eastern) induced distinct patterns of the bottom circulation. Westerly wind caused two cyclonic eddies in the bottom layer - a strong one at the northern part of the Gulf and the weak vortex in the southern area. On the contrary, the easterly wind generated one anticyclonic bottom eddy centrally located in the Gulf of Gdańsk.

The most intensive bottom flows with velocities exceeding $0.5 \mathrm{~m} / \mathrm{s}$ appeared in the western open part of the Gulf due to winds from $\mathrm{W}, \mathrm{NW}$ and $\mathrm{N}$ directions. During winds from NE and $\mathrm{E}$, the bottom currents reached velocities of $0.1-0.3 \mathrm{~m} / \mathrm{s}$. Winds from southern direction sector (SE, S, SW) induced bottom currents with velocities of $0.05-0.3 \mathrm{~m} / \mathrm{s}$. The weakest bottom flows appeared as the effect of winds from S and SW directions with characteristic bottom-flow speeds of only 0 $0.2 \mathrm{~m} / \mathrm{s}$ (see Fig. 4). Such winds cause less intense bottom flows in the central area of the Gulf (smaller than $0.05 \mathrm{~m} / \mathrm{s}$ ) that are rather insignificant for bottom processes.

In Puck Bay, sheltered by the Hel Peninsula, bottom velocities due to wind-driven currents are low independently on wind direction, up to $0.2 \mathrm{~m} / \mathrm{s}$, with the exception of $\mathrm{E}$ and SE wind directions, for which the strong jet bottom flow along the Hel Peninsula occurs.

It should be noted that the discussed above bottom - velocity fields may be unrealistic and the bottom-flow speed overestimated. That overestimation can be explained by the fact that in real storms, it is very unlikely, if not impossible, for 

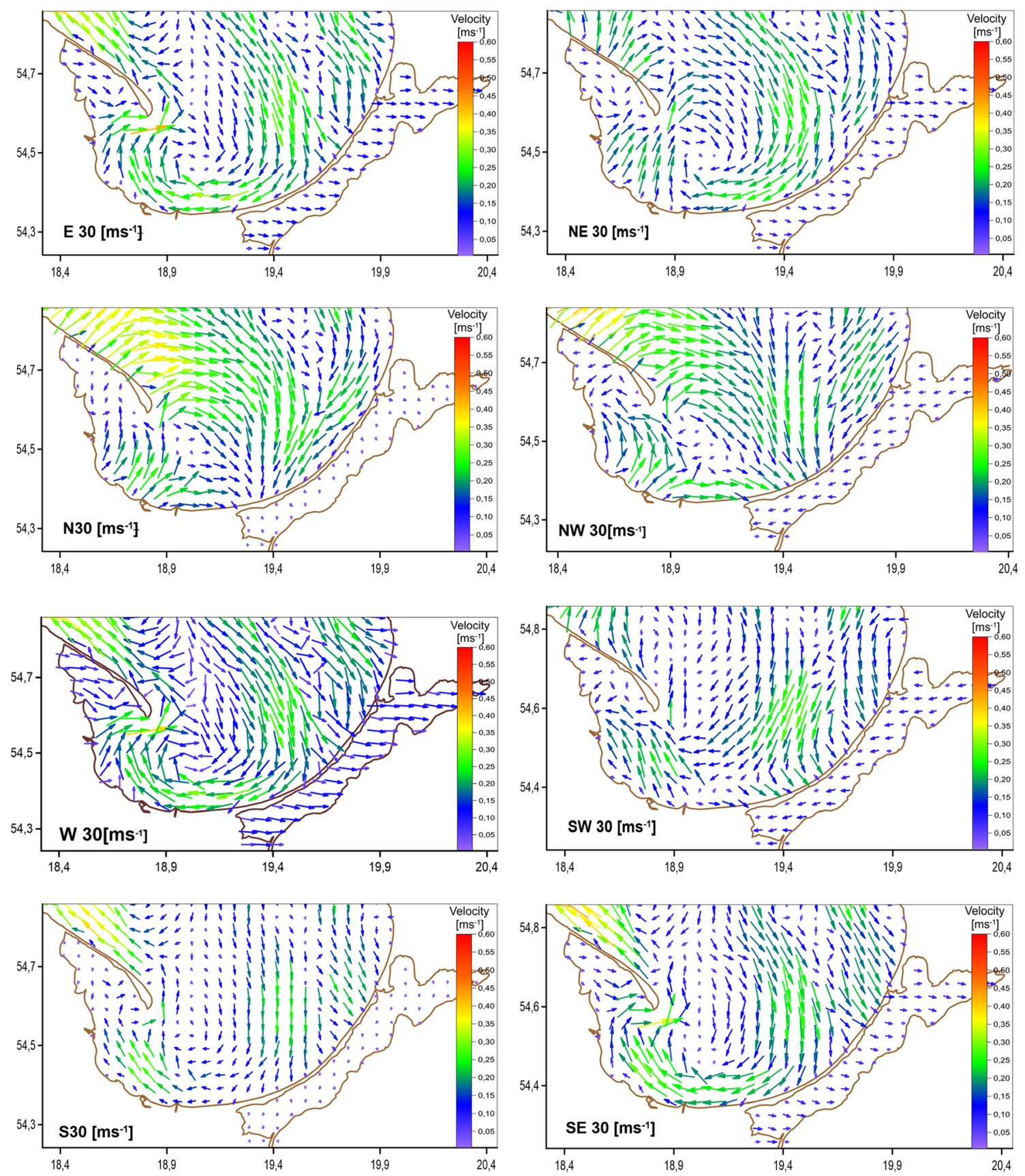

Fig. 4 Bottom current velocity in the Gulf of Gdańsk for eight test artificial storms with $30 \mathrm{~m} / \mathrm{s}$ wind speed from cardinal and sub-cardinal geographical directions

the wind speed to reach its maximum level along the whole critical fetch line and during a relatively long time period, which is the case for the artificial storm test conditions. One may expect that such an artificial and unlikely situation may lead to the very energetic circulation and wave field characterised by extremely high values of estimated hydrodynamic parameters. In order to study realistic bottom-velocity fields appearing during the extreme meteorological conditions, the hydrodynamics of Baltic Sea and Gulf of Gdańsk for the 21 historical storms was hindcast. For the reasons outlined above, the historical storms are less intensive then those artificial described above (see Table 1). Most of those extreme hydrodynamic regimes occurred during similar wind conditions. Namely, the historical storm winds have similar speeds of order $13-16 \mathrm{~m} / \mathrm{s}$ over the Gulf and are blowing from North. Therefore, the resulting bottom velocity fields are similar to one another and for this reason, only the results for the most intense of the 21 storms, i.e. storm no. 10 in Table 1, are presented in this paper in Fig. 9. One can see in this figure that the pattern of bottom current generated during storm no. 10 
resembles the result obtained from simulations of extreme artificial storm with wind from $\mathrm{N}$ direction (see Fig. 4); however, the very strong bottom current through the eastern part of the Gulf does not occur in this case.

Simulations of wind wave fields performed with the use of SWAN model for the eight artificial storms are presented in Fig. 5 in the form of contour plots for significant wave height $H_{\mathrm{S}}$ and the mean wave period $\bar{T}$. On the contour plots of significant wave height, the mean direction of wave propagation $\theta_{0}$ is also presented by using arrows. Figure 6 shows the resulting horizontal root-mean-square bottom particle velocity $u_{\mathrm{rms}}$ for all of the eight extreme test cases. One can see that the largest values of wind wave parameters occur for the northerly winds (blowing from N, NE, NW directions). For those cases, the significant wave height exceeds $18 \mathrm{~m}$ and the mean wave period is greater than $12 \mathrm{~s}$. Those values, obtained for the uniform artificial storms, may be considered unrealistic for the reasons described above in the context of the nearbottom circulation. As one may expect, such extreme wind waves generated considerable water motion characterised by horizontal bottom orbital velocity fields with high values of $u_{\mathrm{rms}}$ in the whole area of the Gulf, except of Puck Bay. The most intensive water motion in the bottom layer generated by the wind waves $\left(u_{\mathrm{rms}}\right.$ above $\left.0.8 \mathrm{~m} / \mathrm{s}\right)$ appeared in the southern and south-eastern and western (up to the Puck Bay border) parts of the Gulf. The maximal values of $u_{\text {rms }}$ up to $1.4 \mathrm{~m} / \mathrm{s}$ may be found along the southern and eastern coast of Gulf of Gdańsk along the Vistula Sandbar and also in the area north of and adjacent to the Hel Peninsula.

In contrast to meteorological conditions with prevailing northerly and north-westerly winds, even extremely strong winds blowing from southern and eastern directions do not produce very intense velocity fields in the bottom layervalues of $u_{\text {rms }}$ in such cases are found to be less than $0.5 \mathrm{~m} / \mathrm{s}$ in the vast area of the Gulf.

In the realistic cases of the 21 hindcast historical storms, the modelled extreme significant wave heights on the northern border of Gulf of Gdańsk basin were found to be in a range of about 5-8 m (see Table 1). The most intense of those historical storms was the one in November 29, 1988 (storm no.10 in Table 1). The distributions of analysed wave parameters during the peak of that storm, including the resulting characteristics of wave orbital bottom velocity field, i.e. the $u_{\text {rms }}$ values, are presented in Fig. 7. Resulting bottom $u_{\text {rms }}$ values are maximal, being namely in the range of $0.5-1.4 \mathrm{~m} / \mathrm{s}$, within in the narrow strip adjacent to the Vistula Sandbar along the Gulf's south-eastern coast.

In order to get some insight about potential sediment transport in the area of particular interest in the Gulf of Gdańsk, the routes of virtual particle tracers located initially near the seabed have been simulated within this research study. They are presented in Figs. 8 and 9. The initial horizontal positions of the particle tracers were selected at two points ZG1 (particle tracer path marked with red) at water depth of $23 \mathrm{~m}$, and ZG2 (green path) at $20 \mathrm{~m}$ depth. That particular selection was made because of the importance of these areas as the likely deposition sites for the sand gathered during dredging works in port of Gdańsk.

The particle tracers were released after $24 \mathrm{~h}$ of simulated flowing process when currents revealed small importance of velocity changes with almost stationary state. Winds from NW through $\mathrm{N}$ to $\mathrm{E}$ induced spreading of particle tracers towards directions consistent with the winds. However, the particle tracers for these wind conditions run aground (at $16 \mathrm{~m}$ of depth) during the first day of their travel except the ZG2 particle tracer which for easterly wind escapes towards the open sea. The trajectories of particle tracers for those winds (NW through $\mathrm{N}$ to E) are short while the particle tracers themselves reached only short way distances due to western and southern vicinity of shore (see Fig. 8). The particle tracers' movement controlled by winds from SE to $\mathrm{W}$ via $\mathrm{S}$ (winds from the southern direction sector) spread out several times further, particularly, trajectories resulted from winds blowing from SE and SW reached distance of 80-100 km. With passage of time, trajectories of particle tracers were shaped by the circulation of the Gulf, not simply reflecting the wind direction but also influenced by the bottom topography and coastline geometry. Trajectories induced by winds from $\mathrm{S}$ and SE show particle tracers migrating to a depth of $50 \mathrm{~m}$ greater than depth of their initial position. On the other hand, particle tracers driven by winds from S and SW spread out at higher levels than their initial depths. This is particularly well pronounced for SW wind particle tracers that emerged to surface layer (see Fig. 8).

It must be emphasised that these results regarding the virtual particle tracers concern only wind-generated bottom currents and entirely neglect wave-generated water motion which, as we showed above, is crucial in most of stormy situations. It means that these results can be interpreted as a partial result providing only preliminary insights into the problem. A more comprehensive approach to the subject requires use of a wave-current coupled model, and this is planned for the future research work. However, due to the oscillatory character of the wavy motion, it may result in relatively low mean values of particle velocities even when values of $u_{\mathrm{rms}}$ are significant. At the same time, the wind-driven circulation despite being much lower, but possessing the character of trends, may still be an important factor to consider while studying the sediment transport problem. 

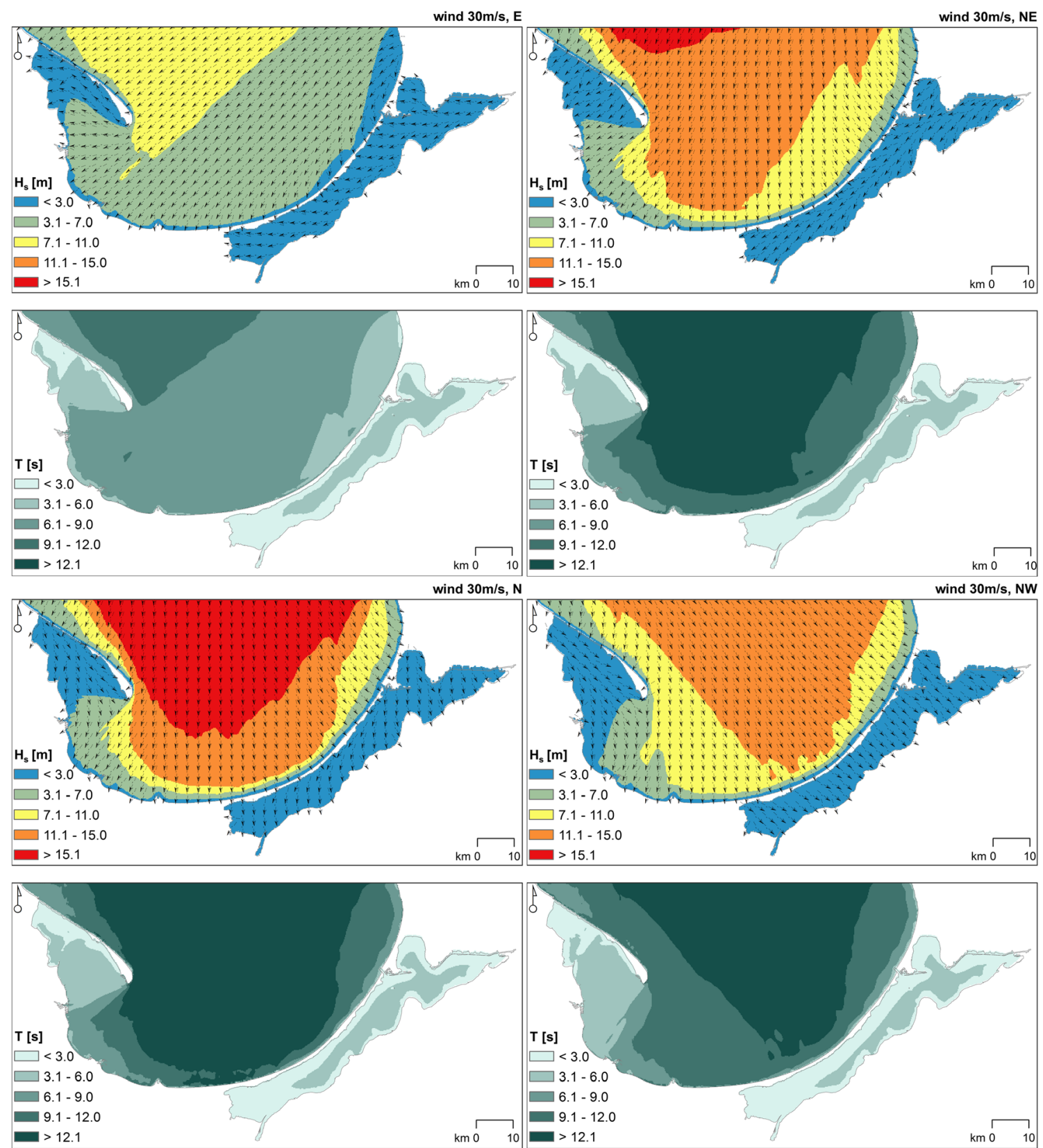

Fig. 5 Results of wind wave modelling with SWAN for eight test artificial storms with $30 \mathrm{~m} / \mathrm{s}$ wind speed from cardinal and sub-cardinal geographical directions: distributions of significant wave height $H_{\mathrm{S}}$ and the mean wave period $\bar{T}$

\section{Discussion and conclusions}

\subsection{Uncertainties in modelling}

The accuracy of wind wave and circulation variables modelled in this study can be discussed under four headings: (i) uncertainty of input data, (ii) physical assumptions of applied models, (iii) effects of numerical procedures applied in and (iv) validation of used models. The numerical wave and current models applied in this study are forced with meteorological REMO reanalysis data, which has been extensively validated (e.g. see Sotillo et al. 2005) and proved to be of a good quality and able to simulate a state of atmosphere with confidence. For the modelling of eight artificial storms, the assumption of persistent simplified uniform steady wind field, with the assumed extreme wind speed, overestimated the 

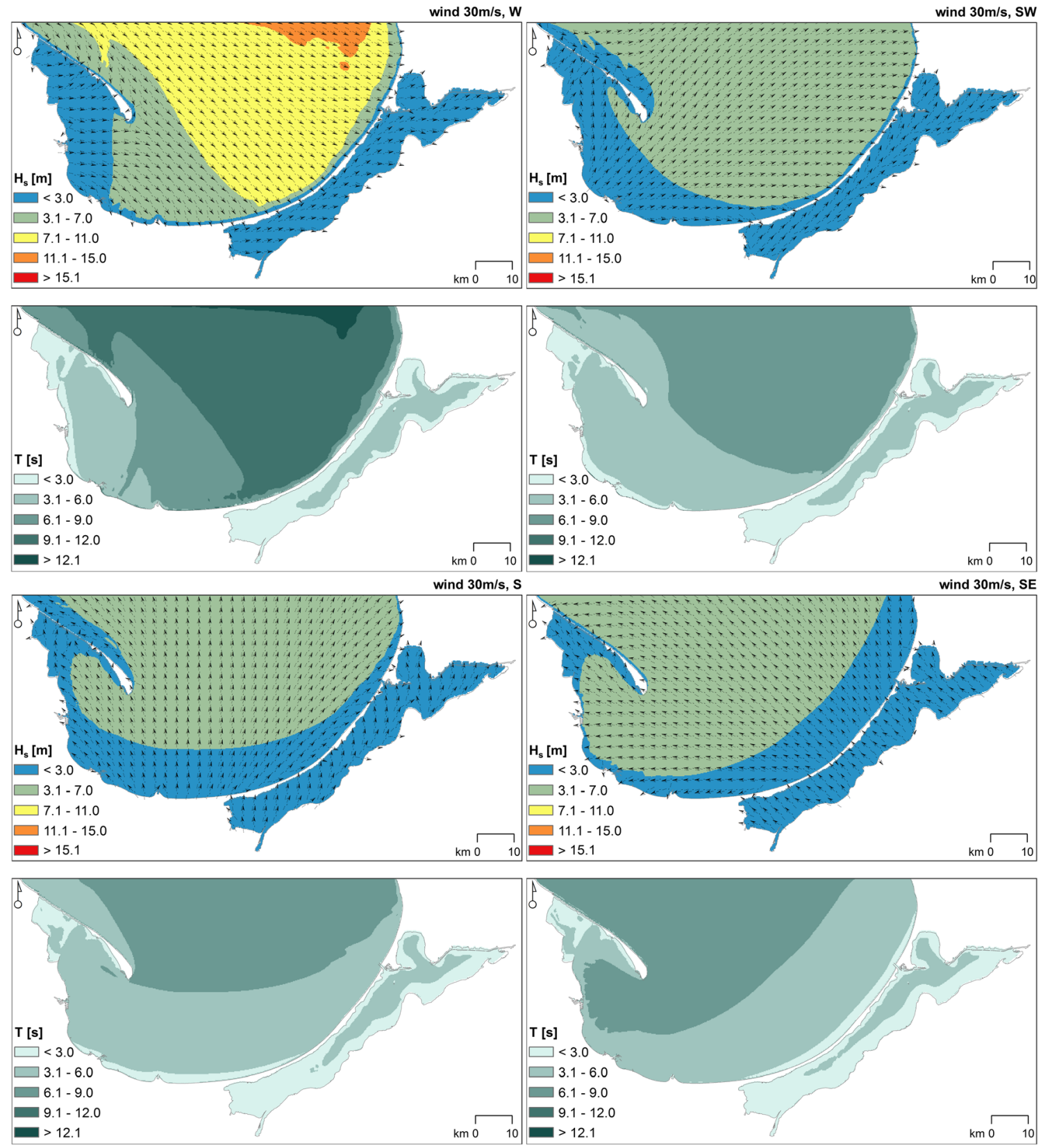

Fig. 5 (continued)

resulting hydrodynamic parameters. It is understood and was discussed in previous section.

It is a major challenge to generate a coherent long-term reanalysis data based on historic observations, mainly due to changes in observing system throughout long periods. Since the 1990s, major research efforts resulted in a great progress in this domain that have led to the setting up reliable long-term datasets. A good example of such comprehensive dataset is the 20CR data. Within the 20CR project, to eliminate shifts in the historical records, the fixed data assimilation system, applying an advanced Ensemble Kalman Filter, has been used. For the same reason, in addition, a fixed numerical weather prediction model was used (see Compo et al. 2011). This approach, together with the sophisticated quality control, allowed for developing dataset being a valuable resource for metocean modelling. However, some shifts in historical records, caused by non-homogeneous observational databases, still remain, which should be noted.

Reanalysis of meteorological data are synoptic observation-based estimates, with rather coarse resolutions in both space and time. By their nature, they are somehow smoothed-down data. Therefore, when used as forcing data to model extreme meteorological events, they may cause certain underestimation of meteo-parameter maxima. Extreme wind gusts in computations carried out over grids of synoptic resolution are actually sub-grid processes, and they are quite 

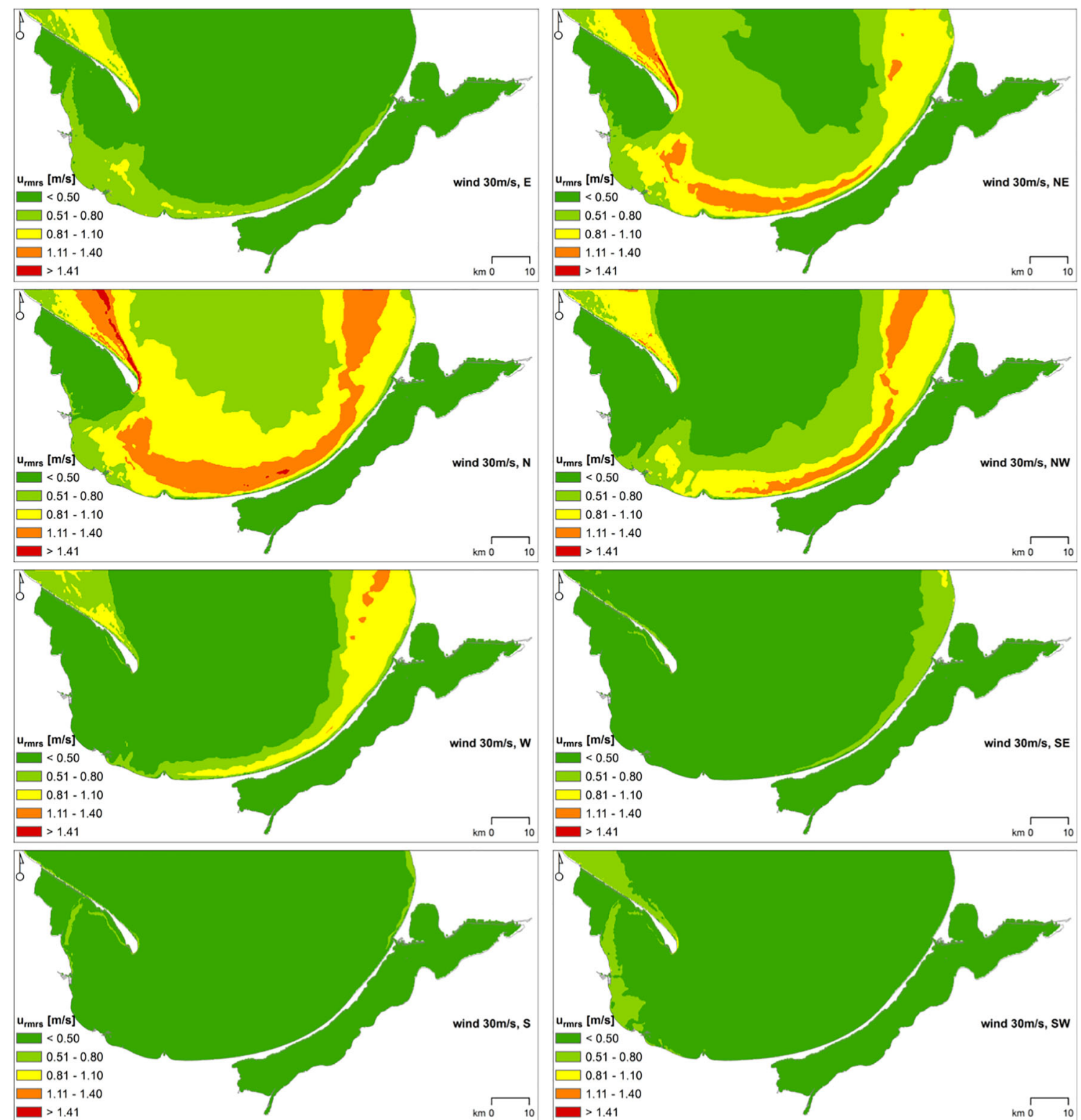

Fig. 6 Results of wind wave modelling with SWAN for eight test artificial storms with $30 \mathrm{~m} / \mathrm{s}$ wind speed from cardinal and sub-cardinal geographical directions: distributions of bottom horizontal root mean square orbital velocity $u_{\text {rms }}$

difficult to model with a very high accuracy. Both NOAA and REMO reanalysis data (see Cieślikiewicz and PaplińskaSwerpel 2008) are biased in this respect. The REMO database was used to prepare the forcing data for the numerical models applied within the HIPOCAS project and then served as forcing data for the hydrodynamic models used in this study. It means that there are of course some uncertainties introduced in the hindcast results concerning extreme storm events. However, there are works proving that the HIPOCAS data reproduce extreme wind events in a more realistic way than the global NOAA reanalysis data does (Sotillo et al. 2006).

In our study, the physical model of wave motion neglected the wave-current interactions (including inducing currents by waves) and the asymmetry of waves. Furthermore, in modelling of hydrodynamics, sub-grid mixing processes were represented by Mellor and Yamada level 2.5 closure scheme (Mellor and Yamada 1982). Although this parametrisation is widely used in coastal ocean application, it should be noted that the choice of turbulence closure scheme can have an impact on resulting circulation, especially in areas close to the shore. However, this impact seems negligible in the bottom layer of the sea (Durski et al. 2004). On the whole, the physical assumptions made in this approach seem reasonable for the studied area and rather do not induce significant errors of modelled quantities.

The next step of modelling is the choice of appropriate numerical model. Numerical accuracy of used models (WAM, SWAN and M3D) was an object of numerous studies. 

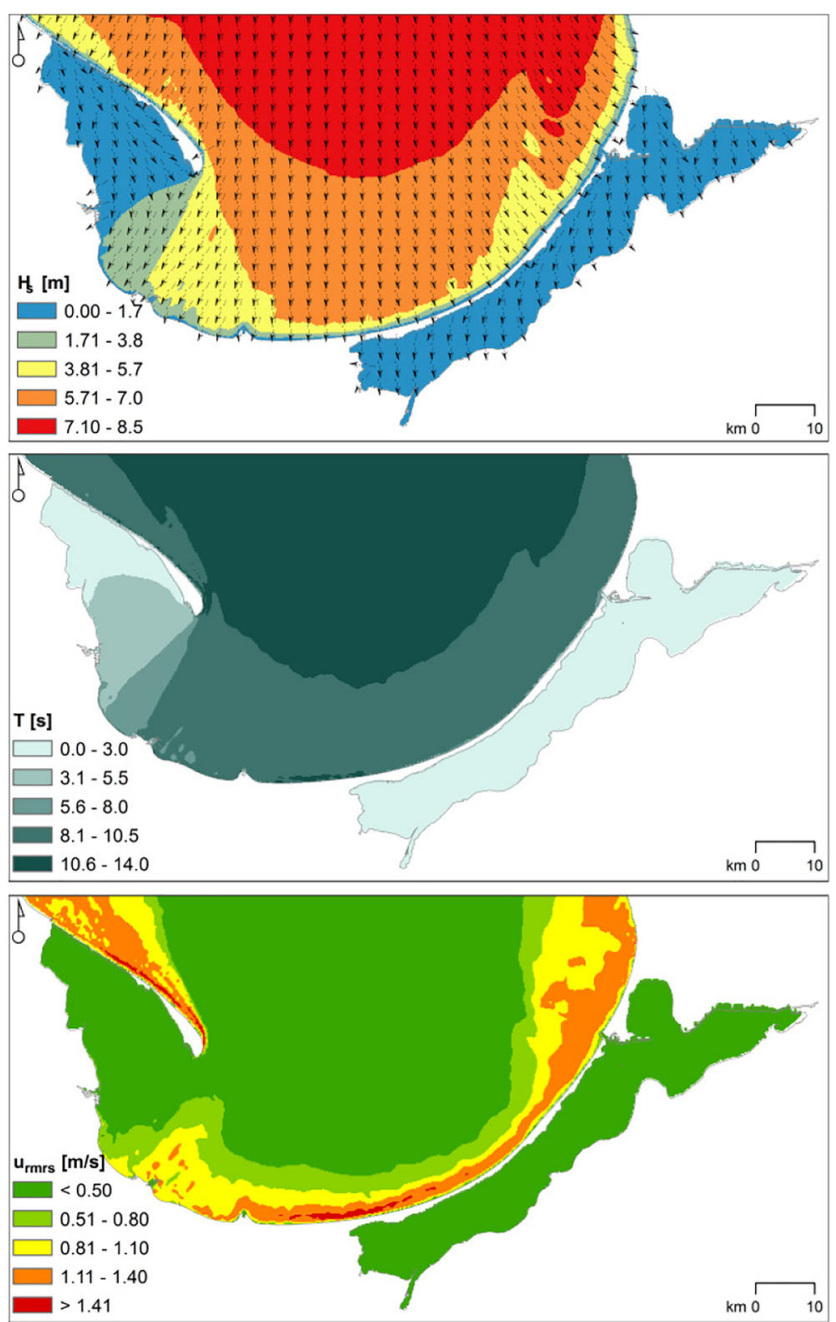

Fig. 7 Results of wind wave modelling with SWAN for the peak of extreme storm no. 10: distributions of significant wave height $H_{S}$, mean wave period $\bar{T}$, and bottom horizontal root mean square orbital velocity $u_{\mathrm{rms}}$

Wave models applied have different numerical schemes; WAM is resolved by explicit while SWAN by implicit scheme (Booij et al. 1999). Even though the propagation scheme in SWAN is fairly diffusive, for small areas (horizontal scales up to $25 \mathrm{~km}$ ), this effect can be neglected. It is worth to mention some possible underprediction by SWAN of the peak wave period, as reported by Zijlema and van der Westhuysen (2005).

In circulation modelling, the finite difference equations of the M3D model were approximated with the second-order accuracy in space and time to conserve energy, temperature, salinity, mass and momentum. For assurance of computational stability, the CFL (Courant-Friedrichs-Levy) condition has been complied with. The M3D model was subjected to basic procedural steps for calibration, verification and validation. In particular, during the validation, it was tormented by changes of sadden and violent forcing and pressed for long time conditions, especially associated with extreme events, to check if they can destroy numerical solutions (Jędrasik 2005). As it was described in Sect. 2, two important numerical improvements were made, in order to minimise the possibility of errors and prevent oscillations and unrealistic values of modelled quantities. Firstly, the improvements in the central difference scheme in advection transport equations were made, and secondly, a division into subregions similar in terms of hydrology was introduced.

Circulation modelling results would also contain errors due to nesting techniques allowing applying a higher spatial resolution for limited area of the Gulf of Gdańsk. In order to minimise errors of that kind, for hydrodynamic modelling, a two-way nested model was employed. This approach enabled interaction in two directions: in one direction, coarser $\rightarrow$ finer grid, model allows to pass errors from coarser resolution solution to the nested one. In the opposite direction, finer $\rightarrow$ coarser grid a more accurate solution, obtained in higher resolution, was applied in the area with coarse resolution, to improve it.

Generally, estimation of complicated modelling errors is very difficult. Reliable in-situ measurements of bottom velocity, especially in the storm conditions analysed in this study, are particularly difficult. On the other hand, $u_{\mathrm{rms}}$ is modelled as a function of wave energy. What is more, under some assumptions, there is a relation that links $u_{\mathrm{rms}}, H_{\mathrm{S}}$, and $\bar{T}$. It is therefore possible to estimate inaccuracy in the modelled $u_{\mathrm{rms}}$ based on inaccuracy of wave energy, or wave height and period, which can be estimated based on data from wave buoys. Such a validation of the SWAN configuration, as used in this paper, has been conducted based on single-point buoy measurements in the vicinity of Lubiatowo, Poland. It was shown that the SWAN model underestimated $H_{\mathrm{S}}$ up to $10 \%$, especially for high values of $H_{\mathrm{S}}$ and for shallow regions (Reda and Paplińska 2002). Additionally, the WAM model, which provides the boundary conditions for SWAN, also tends to underestimate values of $H_{\mathrm{S}}$ and $\bar{T}$. Modelling results of WAM, with the model configuration as used in this research, were validated against buoy measurements within the frame of the PROZA project (Cieślikiewicz et al. 2014); estimated underestimations were of about $2 \%$ for $H_{\mathrm{S}}$ and $9 \%$ for $\bar{T}$. Regarding the M3D model, in view of hitherto lack of current measurements, the model was submitted to comprehensive validation against long-term observations of sea level, salinity, temperature and satellite images of SST. Quite satisfactory correlation coefficients were obtained (Jędrasik 2005). However, some direct comparisons of modelled current data against measurements have been possible. Series of the currents recorded by the ADCP at $1 \mathrm{~m}$ depth at a station near the Vistula Sandbar over a 5-month period was compared with the modelled values. Modelled velocity currents were underestimated by about $4.2 \mathrm{~cm} / \mathrm{s}$ with RMSE error of $21 \%$ (Jędrasik and Kowalewski 2010). Though, these results must be interpreted with caution, because uncertainties described 

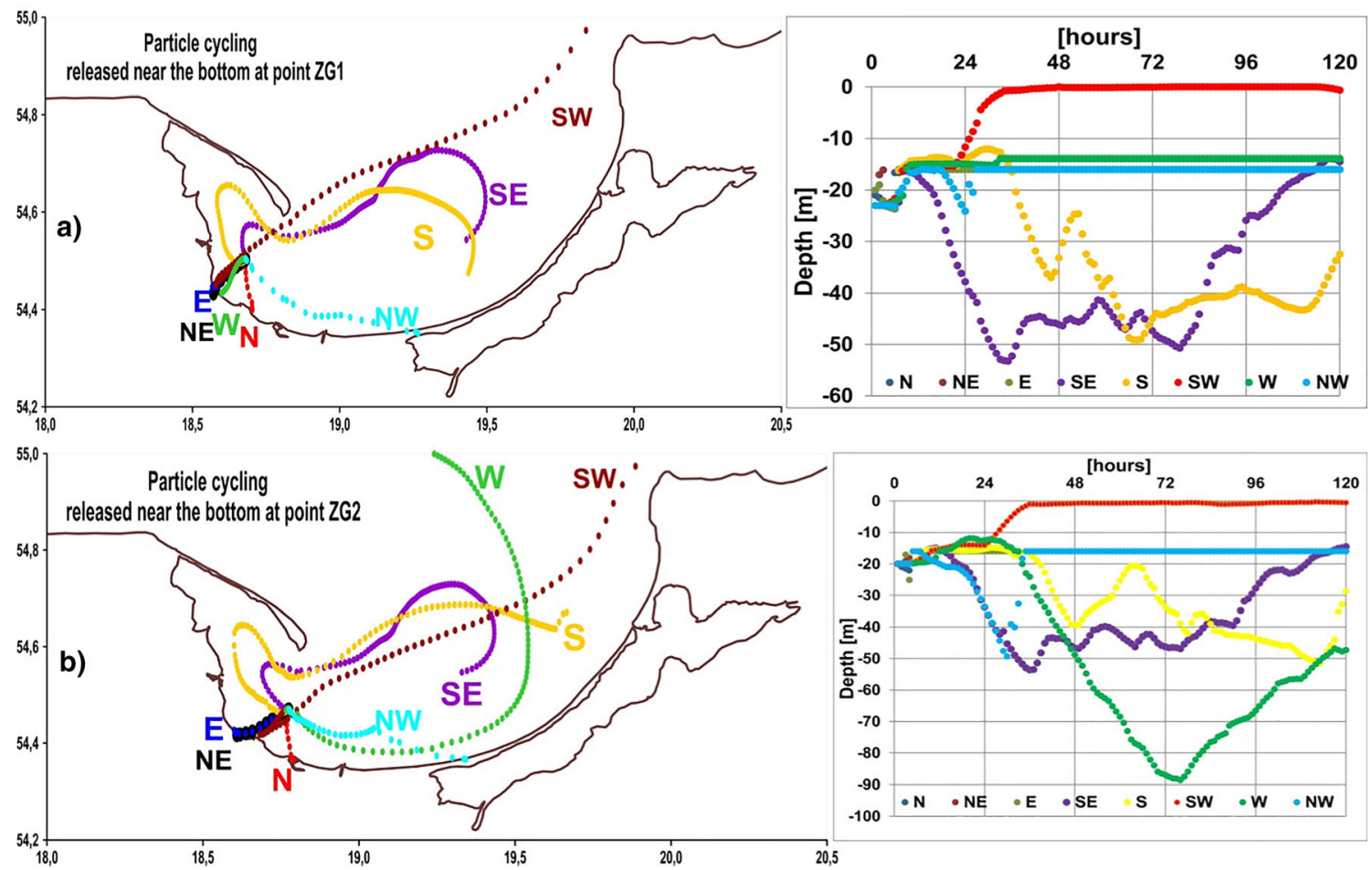

Fig. 8 Trajectories of virtual particle tracers released near bottom at ZG1 and ZG2 points resulted from steady wind-driven currents induced by artificial storms with $30 \mathrm{~m} / \mathrm{s}$ wind speed from principal geographical directions

above depend on physical conditions varying over the grid, such as depths and resulting wave and currents parameters. In conclusion, the quantitative estimate of the accuracy of bottom velocity requires more comprehensive in-situ measurements and will be the subject of further investigation.

\subsection{Discussion of results}

In this paper, the most extreme storm conditions which may occur in the Gulf of Gdańsk have been examined in order to assess the possible maximum bottom velocities to appear in this area. To this end, the extreme hydrodynamic conditions were computed based on historical data with use of numerical wind wave spectral models and numerical circulation models. The knowledge of maximum bottom velocities is an important factor in planning of many kinds of marine engineering investments. For example, the reliable estimation of bedload transport at the specific locations for extreme wind wave and sea current conditions may be of great importance in planning dredging works in the near-shore zone (for example in harbours and within their vicinity). Nowadays, the dredging material gathered is moved to deposition sites usually located at relatively deep waters (about 30-60 m). The better knowledge on kinematics in the bottom layer of coastal zone may allow to consider deposition sites located at shallower waters (at depths of order of 18-20 m) in regions located closer to the shoreline, and thus easier and more effectively manageable deposition sites for potential future use, for example, as sources of sandy material for various engineering purposes. Another example is offshore and coastal engineering and related needs for a good knowledge of motion regimes during extreme storm events for prediction of stability of engineering structures.

The principal aim of hindcasting of 21 most severe historical storms in the last 44 years was to recognise the critical meteorological conditions - critical in terms of generated wind wave field. In our study, we focus on bottom velocities due both to wind wave and to currents. We cannot be certain that meteo conditions generating the highest wind wave heights are also critical in regard to bottom velocities (current and wave induced). To gain a deeper insight into the bottom velocity regime, we examined the hydrodynamics for the basin of interest, during various meteorological conditions, for eight artificial uniform storms with different assumed winds for all cardinal and sub-cardinal directions. However, it should be emphasised that the bottom velocity fields, obtained for those artificial storms, may be overestimated and are, at the same time, very unlikely in real storms.

It was found in this study that wave-induced bottom velocities are greater than velocities induced by currents, during northerly winds that are critical for the area of Gulf of Gdańsk in the sense that they can cause extreme waves and most significant wind-driven circulation. Namely, the maximum values of $u_{\text {rms }}$ up to $1.4 \mathrm{~m} / \mathrm{s}$ may be noticed at the contour plots of that parameter created for northerly artificial storms (NW, N, NE)—see Fig. 6. For historical storm no. 

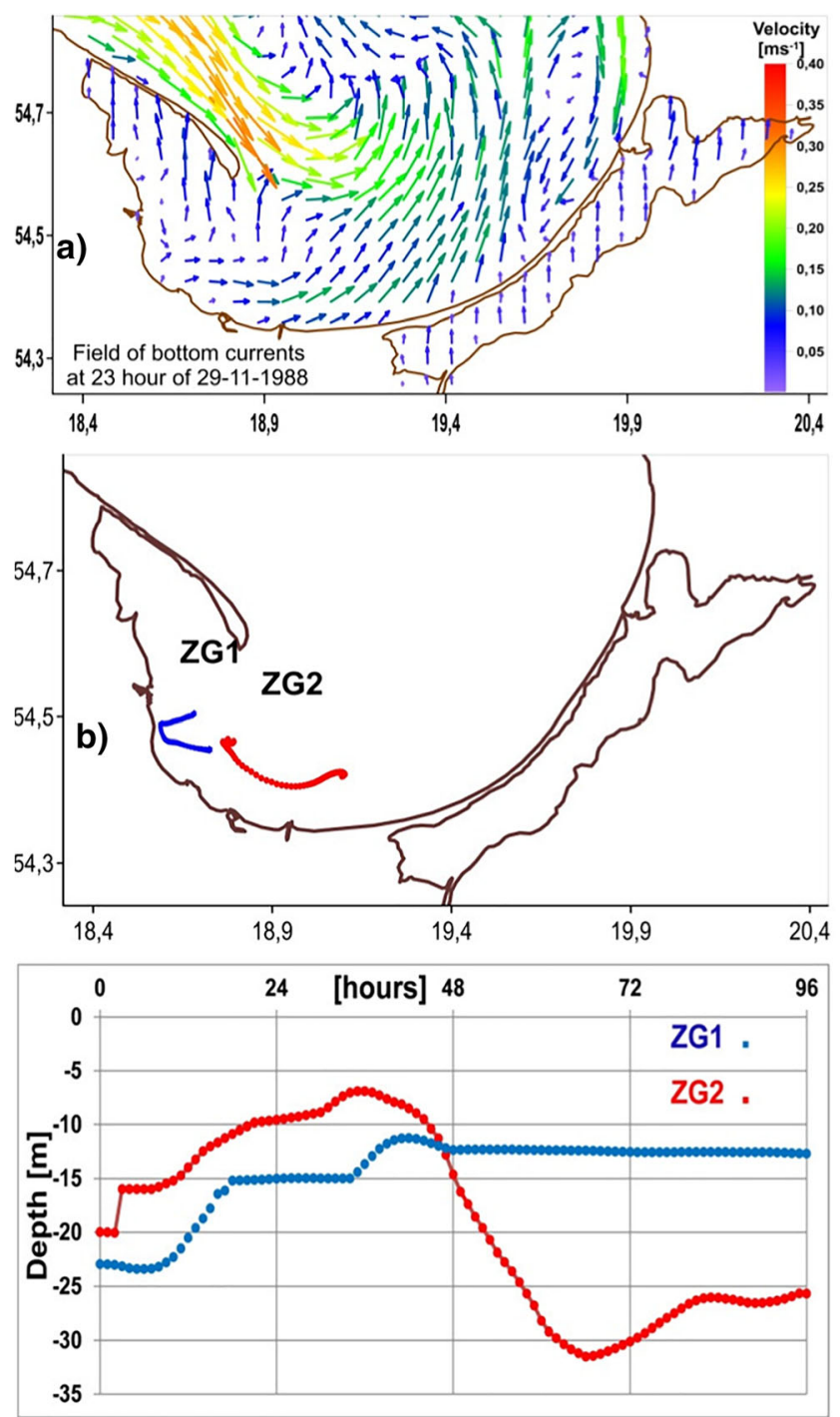

Fig. 9 Bottom current velocity and paths of bottom particle tracers modelled with M3D for the peak of extreme storm no. 10. The particle tracers are released near bottom at ZG1 and ZG2 points at the peak of the storm - time is counted from that moment in hours

10 , maximum $u_{\mathrm{rms}}$ of the same order of $1.4 \mathrm{~m} / \mathrm{s}$ appears in the southern part of the Gulf of Gdańsk (see Fig. 7). For this particular storm, the wind speed over the Gulf of Gdańsk was about $16 \mathrm{~m} / \mathrm{s}$ over the central part of the Gulf. The significant wave height $H_{\mathrm{S}}$ reached a maximum value of order of $8.5 \mathrm{~m}$, during the peak of the storm, at the northern border of Gulf of Gdańsk. For those northerly artificial storms as well as for extreme storm no. 10, the current velocities in the bottom layer were of order $0.1-0.15 \mathrm{~m} / \mathrm{s}$, i.e. they are smaller by an order of magnitude than the wave-induced bottom $u_{\mathrm{rms}}$ (see Fig. 4). The same relation of orders of magnitude holds true for wind wave and current bottom velocities modelled for northern artificial storms (NW, N, NE). For the southerly winds, both of those kinds of velocities are of comparable order. However, the southerly winds do not create extreme sea states in the area of interest.
Until this study, there was not much research done on extreme bottom water motion for the area of Gulf of Gdańsk. Therefore, there is a strong demand for estimation, at least to a first approximation, of those extreme bottom velocity fields. Such situation excuses making some compromising assumptions that simplify the problem and allow one to get some preliminary insights. In this respect, the results obtained in this study should not be treated as exact solutions. The following assumptions have been made: firstly, the wave-current interactions were neglected, i.e. bottom-velocity fields originated from wind wave and wind currents are computed independently of each other. Secondly, as far as modelled wind currents represent actual bottom flows, the wave-generated bottom velocities, characterised by the root mean square velocity, represent only the intensity of wavy motion, which actually has an oscillatory character and the degree of asymmetry of this motion can be very important. The asymmetry of the wavy motion may have a strong effect on the characteristics of sediment transport. In this paper, we focus on the extreme values of velocities only; thus, the effect of wave asymmetry is not considered here. Owing to differences in the physical meaning of the root-meansquare characteristics of wave orbital velocities, and current-generated velocities, the calculation and the analysis of their sum is not feasible. Also, wave-induced currents were neglected in this research study.

The wave-induced near-seabed velocities in the Gulf of Gdańsk, at water depths up to about $20 \mathrm{~m}$, during most severe storms, are greater by an order of magnitude than the current velocities. Therefore, they are most influential on the sand suspension processes and on the state of the near-seabed boundary layer. However, since small amplitude wave theory assumptions are made in this work, the wave orbital velocities are supposed to have an oscillatory character with an average close to zero, and we do not consider them when particle tracers' trajectories are computed. On the contrary, even though the current velocities are much smaller, they do not oscillate and their value may be significant enough to play a role in shaping the mean particle movement. Thus, when particle tracers' paths are computed, we take into account the current velocities only. This approach is used to simplify the computational procedures. In order to include in numerical computations of the particle tracers' paths both wave and current velocity, one should extend the approach by assuming the non-linear wave theory and by including the wave-current interactions, which are not considered in this work.

Despite all these assumptions, the extreme bottom-velocity fields as estimated in this research work provide very important information about the order and the upper limit of kinematic characteristic in the near bottom layer for the entire Gulf of Gdańsk area. These results are important to determine whether and where the sediment transport may occur. 
Acknowledgements The research described was supported in part by the Polish National Science Centre grant No. 359 DEC-2011/01/D/ST10/ 07668 "Development of a predictive model of morphodynamic changes in the coastal zone". Part of the work has been conducted within the project PROZA, which has been partially funded by the European Union under the Innovative Economy Programme contract No. POIG.010301-00/140/08

Open Access This article is distributed under the terms of the Creative Commons Attribution 4.0 International License (http:// creativecommons.org/licenses/by/4.0/), which permits unrestricted use, distribution, and reproduction in any medium, provided you give appropriate credit to the original author(s) and the source, provide a link to the Creative Commons license, and indicate if changes were made.

\section{References}

Anisimov MV, Zhurbas VM, Paka VT, Subbotina MM, Koshkov GA (2000) Modeling of water exchange dynamics in the Stolpe Channel of the Baltic Sea. Oceanology 40(5):624-630

Blumberg AF, Mellor GL (1987) A description of a three-dimensional coastal ocean circulation model. In: Heaps N (ed) Threedimensional Coastal Ocean models 4. American Geophysical Union, Washington, DC, p 208

Bobakov A (2010) Wind-driven currents and their impact on the morpholithology at the eastern shore of the Gulf of Gdańsk. AHEM 57(2): $85-103$

Booij N, Ris RC, Holthuijsen LH (1999) A third-generation wave model for coastal regions. J Geophys Res 104(C4):7649-7666

Cieślikiewicz W, Herman A (2001) Wind wave modeling over the Baltic Sea and the Gdańsk Bay. Inżynieria Morska i Geotechnika 4:173184 [in Polish]

Cieślikiewicz W, Herman A (2002) Wave and current modelling over the Baltic Sea and the Gdańsk Bay. Proc 28th Int Conf on Coastal Engineering, Cardiff, July 2002 (ICCE 2002), vol I. pp 176-187. https://doi.org/10.1142/9789812791306 0016

Cieślikiewicz W, Paplińska-Swerpel B (2008) A 44-year hindcast of wind wave fields over the Baltic Sea. Coast Eng 55:894-905

Cieślikiewicz W, Paplińska-Swerpel B, GuedesSoares C (2004) Multidecadal wind wave modelling over the Baltic Sea. Proc 29th Int Conf on Coastal Engineering, Lisbon, Sept. 2004 (ICCE 2004). World Scientific Publishing, pp 778-790. https://doi.org/10.1142/ 9789812701916_0062

Cieślikiewicz W, Dudkowska A, Janowczyk R, Roščinski V, Roziewski Sz, Badur J (2014) Wind wave modelling over the Baltic Sea using WAM model and the coupled ocean circulation-wave POM model. Proc 34th Int Conf on Coastal Engineering, Seoul, Korea, 15-20 June, 2014 (ICCE 2014), posters42. https://doi.org/10.9753/icce. v34.posters. 42

Cieślikiewicz W, Dudkowska A, Gic-Grusza G (2016) Port of Gdańsk and port of Gdynia's exposure to threats resulting from storm extremes. JPSRA 7(1):29-36

Compo GP, Whitaker JS, Sardeshmukh PD, Matsui N, Allan RJ, Yin X, Gleason BE Jr, Vose RS, Rutledge G, Bessemoulin P, Bronnimann S, Brunet M, Crouthamel RI, Grant AN, Groisman PY, Jones PD, Kruk MC, Kruger AC, Marshall GJ, Maugeri M, Mok HY, Nordli Ø, Ross T, Trigo R, Wang X, Woodruff SD, Worley S (2011) Review article - the twentieth century reanalysis project. Q J R Meteorol Soc 137:1-28

Donat M, Renggli D, Wild S, Alexander L, Leckebusch G, Ulbrich U (2011) Reanalysis suggests long-term upward trends in European storminess since 1871. Geophys Res Lett 38:L14703
Dudkowska A, Gic-Grusza G (2017) Wave-induced bedload transportsouthern Baltic coastal zone study. Andean Geol 23(1):1-14. https:// doi.org/10.1515/logos-2017-0001

Durski SM, Glenn SM, Haidvogel DB (2004) Vertical mixing schemes in the coastal ocean: comparison of the level 2.5 Mellor-Yamada scheme with an enhanced version of the K profile parameterization. J Geophys Res 109:C01015. https://doi.org/10.1029/2002JC001702

Dvornikov AY, Martyanov SD, Ryabchenko VA, Eremina TR, Isaev AV, Sein DV (2017) Assessment of extreme hydrological conditions in the Bothnian Bay, Baltic Sea, and the impact of the nuclear power plant "Hanhikivi-1" on the local thermal regime. Earth Syst Dynam 8:265-282. https://doi.org/10.5194/esd-8-265-2017

Fal B, Bogdanowicz E, Czernuszenko W, Bobrzyńska I, Koczyńska A (1997) Characteristic runoffs of the main Polish rivers in the years 1951-1990, Research Materials, Series of Hydrology and Oceanology, Institute of Meteorology and Water Management, Warsaw, No. 21, 143 pp [in Polish]

Guimarães PV, Farina L, Toldo EE Jr (2014) Analysis of extreme wave events on the southern coast of Brazil. Nat Hazards Earth Syst Sci 4: 3195-3205. https://doi.org/10.5194/nhess-14-3195-2014

Haney RL (1991) On the pressure gradient force over steep topography in sigma coordinate ocean models. J Phys Oceanogr 21:610-619

Hedley M, Yau K (1998) Radiation boundary conditions in numerical modelling. Mon Weather Rev 116:1721-1736

Hellerman S, Rosenstein M (1983) Normal monthly wind stress over the world ocean with error estimates. J Phys Oceanogr 13:1093-1104

Herman A, Jankowski A (2001) Wind- and density-driven water circulation in the southern Baltic Sea: a numerical analysis. Task Q 5(1): 29-58

Herman A, Jędrasik J, Kowalewski M (2011) Numerical modelling of thermodynamics and dynamics of sea ice in the Baltic Sea. Ocean Sci 7:257-276. https://doi.org/10.5194/os-7-257-2011

Hurrell (1995) Decadal trends in the North Atlantic oscillation and relationships to regional temperature and precipitation. Science 269: 676-679

Jaagus J, Suursaar U (2013) Long-term storminess and sea level variations on the Estonian coast of the Baltic Sea in relation to large-scale atmospheric circulation. Estonian. J Earth Sci 62(2):73-92

Jankowski A (2000) Wind induced variability of hydrological parameters in the coastal zone of the southern Baltic Sea-numerical study. Oceanol Stud 29(3):5-34

Jankowski A (2002) Application of a $\sigma$-coordinate baroclinic model to the Baltic Sea. Oceanologia 44(1):59-90

Jędrasik J (1997) A model of matter exchange and flow of energy in the Gulf of Gdańsk ecosystem - overview. Oceanol Stud 26(4):3-20

Jędrasik J (2005) Validation of the hydrodynamic part of the ecohydrodynamic model for the southern Baltic. Oceanologia 47(4): $1-25$

Jędrasik J (2014) Retrospective modelling and forecasting of the Baltic Sea hydrodynamics. Univ. of Gdańsk Publ., Gdańsk, pp 190 [in Polish]

Jędrasik J, Cyberski J (2000) The water exchange in estuarine lakes of the southern Baltic sea as on the Gardno Lake example. Oceanol Stud 29(4):43-66

Jędrasik J, Kowalewski M (2010) Modelling of the Vistula river plume into the Gulf of Gdańsk, ECOOP IP, Report of WP6, No: S.6.1.1$6.1 .4,1-12$

Jędrasik J, Cieślikiewicz W, Kowalewski M, Bradtke K, Jankowski A (2008) 44 years hindcast of the sea level and circulation in the Baltic Sea. Coast Eng 55:849-860

Jönsson A, Browman B, Rahm L (2003) Variations in the Baltic Sea wave fields. Ocean Eng 30(1):107-126. https://doi.org/10.1016/S00298018(01)00103-2

Kannen A, Jẹdrasik J, Kowalewski M, Ołdakowski B, Nowacki J (2004) Assessing catchmentcoast interactions for the bay of Gdansk. In: 
Schernewski G, Löser N (eds) Managing the Baltic Sea, coastline rep 2, pp 155-165

Komen GJ, Cavaleri L, Donelan M (1996) Dynamics and modelling of ocean waves. Cambridge University Press, Cambridge $532 \mathrm{pp}$

Kowalewski M (1997) A three-dimensional hydrodynamic model of the Gulf of Gdańsk. Oceanol Stud 26(4):77-98

Kowalewski M (1998) Coastal upwellings in stratified shallow sea based on Baltic Sea as an example, Ph. D. Thesis, Uniw. Gd., Gdynia, $83 \mathrm{pp}$ [in Polish]

Kowalewski M (2002) An operational hydrodynamic model of the Gulf of Gdańsk, research works based on the ICM's UMPL numerical weather prediction system results, Fizyka Atmosfery, Wyd. ICM, Warszawa, pp 109-119

Kowalewski M, Kowalewska-Kalkowska H (2011) Performance of operationally calculated hydrodynamic forecasts during storm surges in the Pomeranian Bay and Szczecin lagoon. Boreal Environ Res 16(A):27-41

Kowalewski M, Jankowski A, Gajewski J, Piotrowski M, Jędrasik J, Kowalewska M, Ślimak A (2009) Upgrade of existing model M3D UG, implementation of data assimilation routines in the model M3D, implementation of assimilation method of the SST rep. ECOOP, 036355, S5.2.3.6, 1-52

Kowalik Z (1990) Currents. In: Majewski A (ed) Gulf of Gdańsk. Geolog. Publ., Warsaw 502 pp [in Polish]

Krężel A (1997) A model of solar energy input to the sea surface. Oceanol Stud 26(4):21-34

Kriezi EE, Broman B (2008) Past and future wave climate in the Baltic Sea produced by the SWAN model with forcing from the regional climate model RCA of the Rossby Centre. US/EU-Baltic International Symposium, IEEE/OES. https://doi.org/10.1109/ BALTIC.2008.4625539

Lehmann A, Getzlaff K, Harlaß J (2011) Detailed assessment of climate variability in the Baltic Sea area for the period 1958 to 2009. Clim Res 46:185-196

Leonard BP (1991) The ULTIMATE conservative difference scheme applied to unsteady one-dimensional advection. Comput Methods Appl Mech Eng 88:17-74

Matulla C, Schoener W, Alexandersson H, von Storch H, Wang XL (2008) European storminess: late 19th century to present. Clim Dyn 31:125-130

Mellor GL, Yamada T (1982) Development of a turbulence closure model for geophysical fluid problems. Rev Geophys 20:851-875

Oiao F, Chen LC, Zhao W, Pan Z (1999) Study of wind, wave, current extreme parameters and climatic characters of the South China Sea. Mar Technol Soc J 33(1):61-68. https://doi.org/10.4031/MTSJ.33. 1.8

Paka VT, Zhurbas VM, Golenko NN, Stefantsev LA (1998) Izv. RAN. Fiz Atmosfery i Okeana 35(5):713-720 [in Russian]

Pinto JG, Zacharias S, Fink AH, Leckebusch GC, Ulbrich U (2009) Environmental factors contributing to the development of extreme cyclones and their relationship with NAO. Clim Dyn 32:711-737

Reda A, Paplińska B (2002) Application of numerical wave model SWAN for wave spectrum transformation. Oceanol Stud 31(1-2): $5-21$
Robakiewicz M (2000) Influence of the Gdańsk - east wastewater treatment plant on the coastal zone of the Gulf of Gdańsk-hydrodynamic aspects. Oceanol Stud 29(4):99-110

Ruiz S, Gomis D, Sotillo MG, Josey SJ (2008) Characterization of surface heat fluxes in the Mediterranean Sea from a 44-year high-resolution atmospheric data set. Glob Planet Chang 63:258-274

Rutgersson A, Jaagus J, Schenk F, Stendel M, Bärring L, Briede A, Claremar B, Hanssen-Bauer I, Holopainen J, Moberg A, Nordli Ø, Rimkus E, Wibig J (2015) Surface pressure and winds. In: Second assessment of climate change for the Baltic Sea basin. Regional climate studies, springer open, 77-83

Seifert T, Kayser B (1995) A high resolution spherical grid topography of the Baltic Sea. Meereswissenschaftliche Berichte 9. Institut für Ostsee forschung, Warnemünde, pp 72-88

Sepp M (2009) Changes in frequency of Baltic Sea cyclones and their relationship with NAO and climate in Estonia, Boreal. Environ Res 14:143-151

Sepp M, Post P, Jaagus J (2005) Long-term changes in the frequency of cyclones and their trajectories in central and northern Europe. Nord Hydrol 36(4-5):297-309

Sepp M, Mändla K, Post P (2014) On the origins of cyclones entering the Baltic Sea region. EMS annual meeting abstracts 11 EMS 20:14 275

Soomere T, Raamet A (2011) Long-term spatial variations in the Baltic Sea wave fields. Ocean Sci 7:141-150. https://doi.org/10.5194/os-7141-2011

Soomere T, Weisse R, Behrens A (2012) Wave climate in the Arkona Basin, the Baltic Sea. Ocean Sci 8:287-300. https://doi.org/10.5194/ os-8-287-2012

Sotillo MG, Ratsimandresy AW, Carretero JC, Bentamy A, Valero F, González-Rouco F (2005) A high-resolution 44-year atmospheric hindcast for the Mediterranean Basin: contribution to the regional improvement of global reanalysis. Clim Dyn 25:219-236

Sotillo MG, Aznar R, Valero F (2006) Mediterranean offshore extreme wind analysis from the 44-year HIPOCAS database different approaches towards the estimation of return periods and levels of extreme values. Adv Geosci 7:275-278

Svendsen E, Berntsen J, Skogen M, Adlandsvik B, Martinsen E (1996) Model simulation of the Skagerrak circulation and hydrography during Skagex. J Mar Syst 8:219-236

WAMDI Group (1988) The WAM model - a third generation ocean wave prediction model. J Phys Oceanogr 18:1775-1810

Wang DP, Oey L-Y (2008) Hindcast of waves and currents in hurricane Katrina. BAMS. https://doi.org/10.1175/BAMS-89-4-487

Weisse R, von Storch H, Feser F (2005) Northeast Atlantic and North Sea storminess as simulated by a regional climate model 1958-2001 and comparison with observations. J Clim 18:465-479

Zdroik J, Jędrasik J (2009) Validation on-line and estimation of target operational project experiment. Rep. ECOOP, WP5, S5.2.3.1, 1-6

Zhurbas V, Oh I, Paka V (2003) Generation of cyclonic eddies in the eastern Gotland Basin of the Baltic Sea following dense water inflows: numerical experiments. J Mar Syst 38:323-336

Zijlema M, van der Westhuysen AJ (2005) On convergence behaviour and numerical accuracy in stationary SWAN simulations of nearshore wind wave spectra. Coast Eng 52(3):237-256 